\title{
Eight grand challenges in socio-environmental systems modeling
}

\author{
Sondoss Elsawah ${ }^{1,2}$, Tatiana Filatova ${ }^{3}$, Anthony J. Jakeman², Albert J. Kettner ${ }^{4}$, Moira L. Zellner ${ }^{5}$, Ioannis N. \\ Athanasiadis ${ }^{6}$, Serena H. Hamilton ${ }^{2,7}$, Robert L. Axtell ${ }^{8}$, Daniel G. Brown ${ }^{9}$, Jonathan M. Gilligan ${ }^{10}$, Marco A. \\ Janssen $^{11,12}$, Derek T. Robinson ${ }^{13}$, Julie Rozenberg ${ }^{14}$, Isaac I.T. Ullah ${ }^{15}$, Steve J. Lade ${ }^{2,16}$ \\ ${ }^{1}$ Capability Systems Centre, School of Engineering and Information Technology, University of New South Wales, \\ Canberra, Australia \\ ${ }^{2}$ Fenner School of Environment and Society, Australian National University, Australia \\ ${ }^{3}$ Department of Governance and Technology for Sustainability (CSTM), University of Twente, The Netherlands \\ ${ }^{4}$ Community Surface Dynamics Modeling System, INSTAAR, University of Colorado, Boulder, USA \\ ${ }^{5}$ Department of Urban Planning \& Policy, Institute for Environmental Science and Policy, University of Illinois at \\ Chicago, USA \\ ${ }^{6}$ Information Technology, Wageningen University, Netherlands \\ ${ }^{7}$ School of Science, Edith Cowan University, Joondalup, Australia \\ ${ }^{8}$ Department of Computational Social Science and Center for Social Complexity, George Mason University, USA \\ ${ }^{9}$ School of Environmental and Forest Sciences, University of Washington, USA \\ ${ }^{10}$ Department of Earth and Environmental Sciences, Vanderbilt University, USA \\ ${ }^{11}$ School of Sustainability, Arizona State University, Tempe, USA \\ ${ }^{12}$ Center for Behavior, Institutions and the Environment, Arizona State University, Tempe, USA \\ 13 Department of Geography and Environmental Management, University of Waterloo, Waterloo, Canada \\ ${ }^{14}$ Sustainable Development Practice Group, World Bank, Washington DC, USA \\ ${ }^{15}$ Department of Anthropology, San Diego State University, San Diego, USA \\ ${ }^{16}$ Stockholm Resilience Centre, Stockholm University, Stockholm, Sweden
}

\begin{abstract}
Modeling is essential to characterize and explore complex societal and environmental issues in systematic and collaborative ways. Socio-environmental systems (SES) modeling integrates knowledge and perspectives into conceptual and computational tools that explicitly recognize how human decisions affect the environment. Depending on the modeling purpose, many SES modelers also realize that involvement of stakeholders and experts is fundamental to support social learning and decision-making processes for achieving improved environmental and social outcomes. The contribution of this paper lies in identifying and formulating grand challenges that need to be overcome to accelerate the development and adaptation of SES modeling. Eight challenges are delineated: bridging epistemologies across disciplines; multi-dimensional uncertainty assessment and management; scales and scaling issues; combining qualitative and quantitative methods and data; furthering the adoption and impacts of SES modeling on policy; capturing structural changes; representing human dimensions in SES; and leveraging new data types and sources. These challenges limit our ability to effectively use SES modeling to provide the knowledge and information essential for supporting decision making. Whereas some
\end{abstract}

\section{Correspondence:}

Contact S. Elsawah at s.elsawah@unsw.edu.au

\section{Cite this article as:}

Elsawah, S., Filatova, T., Jakeman, A.J., Kettner, A.J., Zellner, M.L., Athanasiadis,I.N., Hamilton, S.H., Axtell, R.L., Brown, D.G., Gilligan, J.M., Janssen, M.A., Robinson, D.T., Rozenberg, J., Ullah, I.I.T., Lade, S.J.

Eight grand challenges in socio-environmental systems modeling

Socio-Environmental Systems Modelling, vol. 2, 16226, 2020, doi:10.18174/sesmo.2020a16226

This work is licensed under a Creative Commons Attribution-NonCommercial 4.0 International License.

\section{Socio-Environmental Systems Modelling}

An Open-Access Scholarly Journal

http://www.sesmo.org 
of these challenges are not unique to SES modeling and may be pervasive in other scientific fields, they still act as barriers as well as research opportunities for the SES modeling community. For each challenge, we outline basic steps that can be taken to surmount the underpinning barriers. Thus, the paper identifies priority research areas in SES modeling, chiefly related to progressing modeling products, processes and practices.

Keywords

Socio-ecological; uncertainty; actionable science; systemic change; decision support

\section{Introduction: Why SES modeling for actionable science?}

Socio-Environmental Systems (SES) modeling involves developing and/or applying models to investigate complex problems arising from interactions among human (i.e. social, economic) and natural (i.e. biophysical, ecological, environmental) systems. SES modeling can be used to support multiple goals, such as informing decision making and actionable science, promoting learning, education and communication (Schlüter et al., 2019). SES models are developed using a diverse set of computational modeling approaches, including system dynamics, Bayesian networks, agent-based models, dynamic stochastic equilibrium models, statistical microsimulation models and hybrid approaches (Kelly et al., 2013). Developed and applied appropriately, SES models can be effective tools to help address socio-environmental issues in systematic and collaborative ways (Pahl-Wostl et al., 2013; Schimel, et al., 2015). Firstly, SES modeling enables the formal representation of complex adaptive systems by integrating qualitative and quantitative methods and data on: system components, interactions among components, and their responses to changes in the exogenous or endogenous drivers (Levin et al., 2013). Secondly, SES modeling allows developers and users to systematically explore and assess the interactive effects of changes in controllable (e.g. policy and its instruments) and uncontrollable (e.g., natural and external system influences) drivers on systems of interest (Hamilton et al., 2015). Thirdly, SES modeling provides a science-informed platform for stakeholders to exchange and consolidate their knowledge towards realizing a shared understanding and potentially accommodating an alternative course of action (Zellner, 2008). With the advent of new techniques, data sources, and computational power on the one hand, and the growing sustainability challenges on the other, the expectation is that SES modeling should be more widely used to inform decision-making at multiple scales (Zellner and Campbell, 2015). Nevertheless, this is not a straightforward endeavor, and both theoretical and methodological challenges abound.

Current societal-policy demands, such as those posed by the UN Sustainable Development Goals and the 2015 Paris Agreement, are pressing, driving most prominently the transformation and development of new markets, and energy, water, and transport infrastructure. Informing the long-term and unintended consequences of such decisions (e.g., natural resource depletion, climate change, pollution, socio-economic disparity) is crucial so as to avoid locking systems into unsustainable pathways. It is therefore timely to promote innovative research around the grand scientific challenges for progressing SES modeling. Grand challenges are interpreted here as key thrust areas where sustained efforts can accelerate high impact research and practice.

\subsection{This paper}

The presented study aims to identify and formulate current grand challenges in SES modeling, in order to propose clear directions for future generations of models and modeling, to both their developers and users. In here a synthesis of the state-of-the-art in SES modeling is presented to inform policy design, identifying persistent issues to address and opportunities for further advances. The presented study also serves as introductory teaching material for educators to present an overview of the current challenges in SES modeling.

The grand challenges were constructed in two steps. Firstly, a thorough literature review of first-hand experiences with developing SES models and previous work on synthesizing the challenges was conducted. This inventory of challenges in SES modeling was further used to elicit the salient ones. Namely, a number of SES modeling experts, including the authors, were asked to add, comment, merge, detail and prioritize to this inventory as a basis for the following step. Secondly, during an international workshop, "Use of socioenvironmental systems modeling in actionable science: State-of-the-art, Open Challenges and Opportunities," held and supported by SESYNC in March 2018, eight grand challenges were identified and elaborated on by an 
interdisciplinary team of experts. Hence, they are a result of a careful selection of issues dispersed through the academic and grey literature, which was further refined through a bottom-up interdisciplinary dialog.

\subsection{Grand challenges in SES modeling}

The eight challenges identified for SES modeling are presented in Figure 1. While some of these eight challenges may well be relevant for other modeling domains, such as more biophysical, environmental or social modeling, the current paper considers them from the position of coupled modeling of social and environmental systems. As discussed through the paper, the coupled nature of any SES modeling effort brings its inherit specifics. We begin with the challenge of epistemological and ontological differences and misunderstandings across disciplines where impediments to SES modeling often first arise (Section 2.1). In Section 2.2, we draw attention to the appropriate treatment of uncertainty throughout the modeling process. Challenges, but also opportunities, arise when one combines quantitative and qualitative methods (Section 2.3) and integrates models across components represented at different and multiple scales (Section 2.4). Better ways for capturing systemic shifts to a new regime with different spatio-temporal dynamics is needed to advance SES modeling (Section 2.5). Modeling human dimension influences is a challenge in and of itself, as meaningful representations of the richness of decision making by the different actors is still in its infancy (Section 2.6). Yet, this dimension is critical if we are to relate environmental and human impacts to controllable causes and invoke stakeholder engagement as a key strategy to tie the SES modeling effort to impacts in practice (Section 2.7). One of the more topical opportunities is the leveraging of new data types and sources, particularly where these bear examination for their ability to add valuable information and reduce modeling uncertainty (Section 2.8).

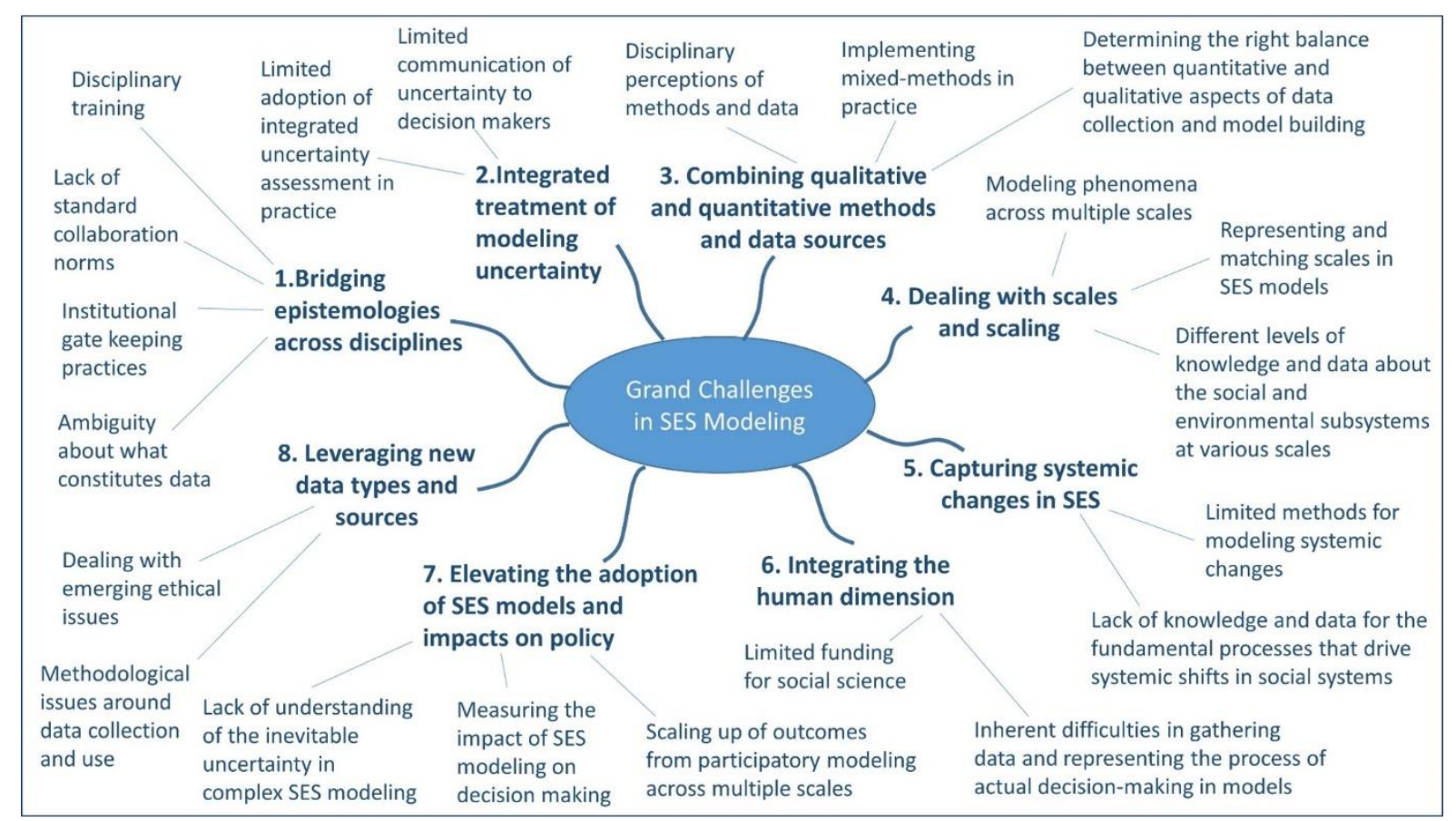

Figure 1: The grand challenges for SES modeling and their underpinning issues

\subsection{Grand challenge 1: Bridging epistemologies across disciplines}

\subsubsection{Nature of the challenge}

The interdisciplinary nature of the study of SES can be a fundamental challenge due to epistemological pluralism (Miller et al., 2008). Scholars from diverse disciplines or approaches are trained in different ways, leading to alternative epistemologies or means of knowing. Misunderstandings and conflicts can arise if this epistemological diversity is not recognized and reconciled (MacMynowski, 2007). These misunderstandings can result in controversies about framing problems and solutions, conflicting evidence, and lead ultimately to the erosion of trust and value of the role of scientific evidence (Sarewitz, 2004). This is a deep and common challenge in interdisciplinary research, and we focus on the following issues as they specifically relate to SES modeling. 
Even the combining of knowledge, ideas and methods from different disciplines within the social sciences (for example, psychology and economics) or within the environmental sciences (e.g. hydrology and ecology) requires additional considerations and building bridges. Yet, connecting the social and natural sciences for SES problems is an effort of another order: it is about integrating different worlds. As one illustration, the fact that the SES are dynamic in nature is not considered by the core philosophy of many social sciences that focus on understanding perceptions or relationships of a particular moment or timeframe. Yet, dynamics is an axiomatic consideration for environmental modelers.

Disciplinary training. Disciplinary training leads to specialized methodological expertise, such as in econometrics, calculus, hydrology, ecology, content analysis, and laboratory research. To address critical topics in SES, however, multiple methods are needed (Poteete et al., 2010). Since disciplinary training does not allow for exposure to and understanding of the underlying assumptions, research philosophy and purposes of diverse methods, it hampers the agreement regarding the proper methodological approach of a problem (Voinov et al., 2018). Interdisciplinary collaboration also poses several challenges in engaging with heterogeneous actors from different backgrounds, including developing a common language to communicate effectively (Athanasiadis, 2017).

Ambiguity about what constitutes data. Differences in epistemological backgrounds can lead to different perceptions regarding the validity, quality and meaning of data, as well as the validity of means to collect and analyze data (Verburg et al., 2016). For example, narratives are commonly used as data in anthropology, but may not be perceived as valuable data by a more natural scientist, while data collected via sensors and webcrawling might be considered big data source by computer scientists, but out of context by a typical humanist.

Institutional gate-keeping practices. Interdisciplinary research on SES has become more established over the last 25 years. There is an increase in well-respected interdisciplinary journals who embrace epistemological diversity (e.g. Ecology \& Society, Nature Sustainability), funding agencies that provide funding opportunities for interdisciplinary research (e.g. Coupled Human-Natural Systems of the US National Science Foundation), and there have been institutional changes at some universities to stimulate interdisciplinary and epistemological pluralism (Crow and Dabars, 2015). Despite these promising changes, traditional funding agencies and publishers are still dominated by disciplinary experts who are less experienced in interdisciplinary science, and therefore tend to reject novel interdisciplinary methodological approaches and theoretical frameworks. On the other hand, interdisciplinary scholars who connect theories and methods of different disciplines are often seen as being shallow in their disciplinary expertise. This viewpoint suggests a lack of appreciation for knowledge integration as deep expertise in its own right, thereby reinforcing existing academic silos.

Lack of standard collaboration norms. Disciplines vary in their norms and practice of collaboration. For example, climate modelers depend on large-scale collaborations to collect data, and develop and execute climate models. This is in contrast to, for instance, anthropologists who do ethnographic work in remote locations and produce narratives of their systematic observations. It is not yet standard across all fields to share well-documented data and model code (Janssen, 2017; Stodden et al., 2018), which hinders the accumulation and meaningful synthesis of knowledge and collaboration between fields. However, there has been increasing awareness of the lack of data and model code sharing and transparency standards in all fields of science (Baker, 2016). This has led funding agencies to request sharing research results in public repositories, and journals to require availability of data used to produce a publication, albeit with limited success to date (Stodden et al., 2018). Nevertheless, the role of science in society will likely stimulate scientific communities to keep improving their transparency and reuse of data and code. This transformation will require a change in research practices, which consequently may increase the acceptance of collaborative open science.

\subsubsection{The way forward}

These epistemological challenges are embedded in the disciplinary structure of our educational and scholarship system. Changing this structure is likely a long haul, but a number of possible developments in the near future will enhance the adoption of epistemological pluralism and facilitate increased capacity to advance SES modeling:

Training in multiple disciplines. Developing a diverse skillset to perform SES modeling requires additional training beyond the typical single-discipline graduate program. A scholar might be still specialized in a particular 
discipline, but would have sufficient basic training in other disciplines to operate in a transdisciplinary environment. Wider availability of short-term immersive training programs for students, postdoctoral scholars and faculty will enable scholars to keep up with the diverse set of methods and approaches needed for integrative SES research. Obvious example topics of short courses are "social science methods for environmental scientists" or "natural sciences tools for social scientists." Learning about relevant features of other disciplines helps bridge epistemologies.

Effective communication and trust in interdisciplinary collaborations. Building trust through effective communication is an important criterion for success in interdisciplinary work (National Research Council, 2006; Poteete et al., 2010). Researchers may have difficulty understanding other disciplines' concepts and jargon, and may mistrust the rigor and reliability of results from other disciplines, stemming from epistemological issues. There is no substitute for extended interactions and conversations among team members to overcome these obstacles, and it can be valuable to make time for these, both before and during the early phases of a project (Athanasiadis, 2017; Lattuca, 2001).

Advancing multi-method approaches. Quantitative model coupling is a practice that has been extensively exercised in the past, and technical solutions have been deployed for linking together constituent models to answer an ever-expanding breadth and complexity of research questions. Work in creating common ontologies with look up tables to translate between discipline-specific terminology aids this process (Peckham, 2014). At the same time, the technical reuse of model component implementations should involve attempts to conceptually align the underlying models (Voinov and Shugart, 2013), so as to avoid intractable models that obscure, rather than illuminate, decision-making (Lee, 1973; Zellner, 2008). In this respect, any attempt to use multiple methods together, including quantitative and qualitative methods, requires not only tools to support the process, but also methodological advancements in how to use methods from different disciplines collectively (e.g., Elsawah et al., 2015). There is little evidence in the literature on the use of multi-methods synergistically in modeling (See Section 2.3), such as in how multiple methods can be combined and used to handle multiple uncertainty sources in an integrated way (See Section 2.2).

Acknowledging the multiple purposes of modeling. The purposes for which models are built include prediction, exploration, learning and communication (Brugnach et al., 2008; Kelly et al., 2013). Quantitative prediction is arguably the purpose most commonly associated with modelling. The diversity of theories of human behavior in social science and the empirical challenge of the complexity of influences on behavior can however make the goal of prediction intimidating for disciplinary experts. In situations of deep uncertainty (see section 2.2.1), approaching modelling with a goal of exploration or learning rather than prediction can build trust among interdisciplinary collaborators and deliver results that more thoroughly reflect this uncertainty. For example, models can be used to explore the consequences of different assumptions about human behavior, ecological dynamics, or social-ecological interactions (Lade et al., 2017) and thereby illustrate the spread of different possible futures (see section 2.2.2). Models can also deliver value for collaborators by providing a tool for testing and learning about emergent consequences of sets of causal assumptions, ultimately improving the models that are used for prediction.

Diverse reward schemes. In order to stimulate a collaborative interdisciplinary scholarship, career reward and funding structures need to change to be more diverse and inclusive (Goring et al., 2014). Instead of a prime focus on research outputs such as the number of published articles and their citations and institutional reputation, other forms of impacts should be recognized. These could include contribution to data sets and code development, network building, social media communication, policy engagement, and realized social and environmental impact.

\subsection{Grand challenge 2: Integrated treatment of modeling uncertainty}

\subsubsection{Nature of the challenge}

In the modeling literature, the main sources of uncertainty are often attributed to: data, model structure, and model parameters (e.g. Kettner and Syvitski, 2016). However, uncertainty sources extend beyond these modelonly sources and pertain to every modeling choice, activity and product, intermediate and final, generated throughout the modeling process. Furthermore, the various sources of uncertainty are often interlinked. For 
example, uncertainty around parameter values can stem from uncertainties associated with model structure, input data and calibration (Deletic et al., 2012). Thus, uncertainty requires a more holistic treatment to identify, manage and report on the influences of the critical sources on objectives (such as predictions or decision options). The need for this holism is captured in the concept of deep uncertainty (Lempert, 2002; Maier et al., 2016), a characteristic of SES modeling in general. Deep uncertainty exists when those involved in a decision do not know, or cannot agree upon, the system model that relates action to consequences, the probability distributions that implies upon the inputs to these models, the consequences to consider and their relative importance.

To date, in most SES modeling studies the focus of uncertainty assessment has been largely on quantitative uncertainty and sensitivity assessment methods and the outcomes achieved from using them. The assessment is typically confined to the narrower analysis of uncertainty around model parameters, inputs and other data but sometimes to alternative model structures. However, uncertainty arises in the various phases of the modeling process, including: defining model purpose and objectives (this includes the type and level of certainty sought); problem framing and model conceptualization (to investigate the appropriate challenge); setting up of model structure, parameters and boundary conditions; the verification/validation process and uncertainty assessment itself (including its qualitative aspects); model coding and numerical implementation; and the communication process and modeling workflows used (Jakeman and Jakeman, 2016). Many of these sources of uncertainty are often overlooked in SES modeling studies.

Recently, there has been growing attention to the development of frameworks for considering uncertainty in a more holistic manner (e.g. Beven, 2016; Guillaume et al., 2016; Maier et al., 2016). These efforts have contributed to improving our conceptual understanding of uncertainty by focusing on:

(1) developing typologies to explicitly characterize uncertainty as a multi-dimensional concept (Di Baldassarre et al., 2016; Maier et al., 2016; Merz et al., 2015; Refsgaard et al., 2007; Walker, 2003);

(2) articulating workflows to break-down and specify the detailed tasks involved in uncertainty management;

(3) providing guidance to practice by linking typologies and workflows to existing methods and tools (Ferson and Sentz, 2016; Harp and Vesselinov, 2012; Ligmann-Zielinska et al., 2014); and

(4) incorporating distinctions between epistemic (knowledge-based) and aleatory (stochastic) uncertainty into uncertainty assessments (Ferson and Setnz, 2016; Harp and Vesselinov, 2012).

Table 1 provides an overview of the potential sources of modeling uncertainties examined by a range of methods.

Table 1: Various methods that can be utilized for dealing with modeling uncertainties

\begin{tabular}{|c|c|c|c|}
\hline Method & Purpose & $\begin{array}{l}\text { Sources of model } \\
\text { uncertainties }\end{array}$ & Examples \\
\hline Mental modeling & $\begin{array}{l}\text { To identify and combine different problem } \\
\text { framings }\end{array}$ & Problem framing & $\begin{array}{l}\text { Elsawah et al., 2015; } \\
\text { Gray et al., } 2014 .\end{array}$ \\
\hline $\begin{array}{l}\text { Critical systems } \\
\text { thinking }\end{array}$ & $\begin{array}{l}\text { To systematically expose assumptions and } \\
\text { biases about representativeness, sources } \\
\text { of knowledge }\end{array}$ & Problem framing & Ulrich, 2013. \\
\hline $\begin{array}{l}\text { Sensitivity analysis } \\
\text { (algebraic, local, } \\
\text { global), Active } \\
\text { Subspaces }\end{array}$ & $\begin{array}{l}\text { To identify model inputs, model } \\
\text { parameters and their combinations that } \\
\text { have significant effect on the model } \\
\text { outputs }\end{array}$ & Parameters and inputs & $\begin{array}{l}\text { Happe, 2005; Jefferson } \\
\text { et al., 2015; Saltelli et } \\
\text { al., } 2006 .\end{array}$ \\
\hline $\begin{array}{l}\text { Crash or stress testing } \\
\text { of model parameters, } \\
\text { structure, and other }\end{array}$ & $\begin{array}{l}\text { To identify the conditions (parametric } \\
\text { values, structure) for establishing } \\
\text { limitations or invalidation of a model. }\end{array}$ & $\begin{array}{l}\text { Data and parameters, and } \\
\text { also structure when } \\
\text { considering alternatives }\end{array}$ & $\begin{array}{l}\text { Coron et al., 2012; } \\
\text { Railsback and Grimm, } \\
2011 .\end{array}$ \\
\hline
\end{tabular}


Table 1 (continued)

\begin{tabular}{|c|c|c|c|}
\hline Method & Purpose & $\begin{array}{l}\text { Sources of model } \\
\text { uncertainties }\end{array}$ & Examples \\
\hline $\begin{array}{l}\text { Uncertainty analysis } \\
\text { via Monte Carlo } \\
\text { methods }\end{array}$ & $\begin{array}{l}\text { To calculate distribution of outputs based } \\
\text { on sampling a distribution of inputs, on } \\
\text { emergence, and on stochasticity of } \\
\text { complex processes. }\end{array}$ & Parameters & $\begin{array}{l}\text { Vrugt et al., 2008; } \\
\text { Railsback and Grimm, } \\
2011 .\end{array}$ \\
\hline $\begin{array}{l}\text { Bayesian inference } \\
\text { (probabilistic) } \\
\text { methods }\end{array}$ & $\begin{array}{l}\text { To infer the a posteriori model parameter } \\
\text { distributions based on a priori parameter } \\
\text { distributions and their likelihood fit to } \\
\text { output data }\end{array}$ & $\begin{array}{l}\text { Mainly data and } \\
\text { parameter distributions; } \\
\text { model structure (and } \\
\text { hence conceptualization) } \\
\text { rarely considered }\end{array}$ & $\begin{array}{l}\text { Kaipio and Somersalo, } \\
\text { 2006; Renard et al., } \\
2010 .\end{array}$ \\
\hline Exploratory analysis & $\begin{array}{l}\text { To search for scenarios that lead to good, } \\
\text { poor and intermediate outcomes, or } \\
\text { specified objectives such as robustness } \\
\text { metrics }\end{array}$ & $\begin{array}{l}\text { Parameters and model } \\
\text { structure }\end{array}$ & $\begin{array}{l}\text { Kwakkel and Pruyt, } \\
\text { 2013; Lempert et al., } \\
\text { 2006; Groves and } \\
\text { Lempert, } 2007 .\end{array}$ \\
\hline $\begin{array}{l}\text { Surrogate models or } \\
\text { model emulation }\end{array}$ & $\begin{array}{l}\text { To approximate the response surface of a } \\
\text { model with a simpler, faster running model } \\
\text { to obtain sensitivity indices and undertake } \\
\text { various types of uncertainty analyses }\end{array}$ & $\begin{array}{l}\text { Model parameters and } \\
\text { inputs }\end{array}$ & $\begin{array}{l}\text { Bungartz and Griebel, } \\
\text { 2004; Rasmussen and } \\
\text { Williams, 2006; Sudret, } \\
2008 .\end{array}$ \\
\hline Identifiability analysis & $\begin{array}{l}\text { To assess ambiguities especially in model } \\
\text { parameterization }\end{array}$ & $\begin{array}{l}\text { Parameters, extensible to } \\
\text { model structure }\end{array}$ & $\begin{array}{l}\text { Walter and Pronzato, } \\
1997\end{array}$ \\
\hline Parameter estimation & $\begin{array}{l}\text { To optimize model parameters for a given } \\
\text { objective function }\end{array}$ & Data, parameters & $\begin{array}{l}\text { Wagener and Wheater, } \\
2006 .\end{array}$ \\
\hline $\begin{array}{l}\text { Multi model analysis } \\
\text { (aka model docking or } \\
\text { model alignment) }\end{array}$ & $\begin{array}{l}\text { To illustrate the impact of different model } \\
\text { structure assumptions }\end{array}$ & Model structure primarily & $\begin{array}{l}\text { Wilensky and Rand, } \\
2007 .\end{array}$ \\
\hline Uncertainty matrix & To prioritize crucial sources of uncertainty & $\begin{array}{l}\text { Communication about all } \\
\text { sources of uncertainty, } \\
\text { including structure, } \\
\text { parameters, and data }\end{array}$ & Janssen et al., 2003. \\
\hline $\begin{array}{l}\text { (Automated) } \\
\text { Scientific Workflows }\end{array}$ & $\begin{array}{l}\text { To capture and automatically run model } \\
\text { experiments, allowing for reproducing } \\
\text { results and model's transparency }\end{array}$ & $\begin{array}{l}\text { Communication about all } \\
\text { sources of uncertainty, } \\
\text { including structure, } \\
\text { parameters, and data }\end{array}$ & Chakladar, 2016. \\
\hline $\begin{array}{l}\text { Numeral, Unit, } \\
\text { Spread, Assessment } \\
\text { and Pedigree (NUSAP) }\end{array}$ & $\begin{array}{l}\text { To prioritize and visualize sources of } \\
\text { uncertainty using qualitative and } \\
\text { quantitative insights about limitations in } \\
\text { existing knowledge, and their implications } \\
\text { to decision making }\end{array}$ & $\begin{array}{l}\text { Communication about all } \\
\text { sources of uncertainty, } \\
\text { including structure, } \\
\text { parameters, and data }\end{array}$ & $\begin{array}{l}\text { Van Der Sluijs et al., } \\
2005 .\end{array}$ \\
\hline $\begin{array}{l}\text { Practice } \\
\text { documentation or } \\
\text { logbooks }\end{array}$ & $\begin{array}{l}\text { To capture the rationale and details of the } \\
\text { methodological choices made throughout } \\
\text { the modeling process, especially at critical } \\
\text { forks, and their implications to the process } \\
\text { itself as well as model's ability to meet its } \\
\text { intended use }\end{array}$ & $\begin{array}{l}\text { Communication about all } \\
\text { sources of uncertainty, } \\
\text { including structure, } \\
\text { parameters, and data }\end{array}$ & $\begin{array}{l}\text { Jakeman et al., 2006; } \\
\text { Lahtinen et al., 2017; } \\
\text { Schmolke et al., 2010; }\end{array}$ \\
\hline $\begin{array}{l}\text { Model auditing and } \\
\text { Extended peer review }\end{array}$ & $\begin{array}{l}\text { To provide independent assessment and } \\
\text { assurance of the quality of the modeling } \\
\text { process and credibility of results, and may } \\
\text { serve as a process to involve stakeholders }\end{array}$ & All the modeling process & Refsgaard et al., 2007. \\
\hline
\end{tabular}


Limited adoption of integrated uncertainty assessment in practice. Despite the recent theoretical and methodological advances provided above, there is still a chasm between these advances and their actual use in practice to inform decision makers about uncertainty. For example, Zare et al. (2017) reveal in their bibliometric analysis of the integrated water assessment and modeling literature the paucity of focus on uncertainty. The gap between theory and practice can reflect differences in deeply rooted epistemological stances (see Section 2.1) and/or inadequate resources being devoted to uncertainty assessment of SES models. Limited adoption of uncertainty assessment may also be attributed to insufficient practical guidelines for linking theory and practice with common and contextualized lessons around best approaches in how to incorporate uncertainty assessments. Example questions for uncertainty considerations in SES modeling are as follows. What is the level of certainty required in the context of the problem specifics (e.g. data limitations, resource constraints, and scale) that sufficiently fit the general purpose of the modeling exercise (e.g. Haasnoot et al., 2014)? How can we employ multi-method approaches to address different sources of uncertainties? Can we rank uncertainty sources based on their influence on objectives? What critical information can be sought to reduce uncertainties to a useful level? Because modeling is a fluid procedure that involves many choices at every step (Lahtinen et al., 2017), progress in achieving best practices for uncertainty characterization and management in the SES modeling process is best facilitated by undertaking case studies and generalizing by sharing the lessons gained.

Limited communication of uncertainty to decision makers. Although communication with decision makers and stakeholders about modeling uncertainty is a high priority, it remains a daunting task in SES modeling. Often the metrics presented to decision-makers are too complex and are difficult to interpret in user-relevant ways. The chasm between the methodological advances in uncertainty management and their actual use may also, in part, stem from the fear that communicating uncertainty to decision makers will slow down the decision-making process or undermine the relevance of scientific information. This fear is rooted in limited and flawed understanding of how people perceive risk information and make decisions under uncertainty (Morgan et al., 2002). Gridlocks often arise when stakeholders have different visions that would lead to different decisions. Acknowledging uncertainty can shift the discussion towards agreeing on a solution that will work in different ways for everyone (e.g., by discussing what needs to be excluded, by whom, and how to proceed), rather than agreeing on a common vision (Kalra et al., 2015). Mismatches between the way technical experts and decision makers interpret uncertainty have contributed to catastrophic misjudgments (Meyer et al., 2006; Vaughan, 1996; Watkins and Bazerman, 2003). Moreover, experts are prone to overconfidence, so it is imperative that researchers be attentive to their subjective biases and the limitations of their results, and to make these clearly visible when they communicate those (Fischhoff et al., 1982; Jasanoff, 2003).

Another related issue is that stakeholders may have difficulty distinguishing structural uncertainty versus uncertainty in model parameters and data. This relates to the lack of training in using models to reason about complex problems. Novices tend to associate uncertainty with lack of data, and so focus their efforts on data collection and analysis. However, structural uncertainty is not resolved with more data unless it reveals structural weaknesses.

Modeling can help us explore the problem space and bound the associated uncertainty especially when incorporating a social component. Many cases that quantified the uncertainty relating to both environmental systems and socio-economic systems found that the uncertainty pertaining to socio-economic systems was at least an order of magnitude larger than that pertaining to environmental components(e.g. Bonzanigo et al., 2015; Kalra et al., 2015). This is because the frequency of change is often higher for socio-economic systems (population growth, economic growth, urbanization) compared to environmental systems, and the uncertainty on the rate of change is sometimes higher as well (with the exception of ecological collapses). For example, most natural hazard risk assessments find that changes in exposure and vulnerability are much more uncertain than changes in hazard for quantifying future risk. Similar findings have been reported by water planning and hydropower planning studies, which have shown that socioeconomic factors, such as demand growth and electricity prices, can be a larger threat than climate change (Jongman et al., 2015).

There is a culture of using models in a predictive mode to inform decision making. Even if uncertainty is given around the predictions in terms of confidence bounds or ranges, the information, in the case of SES especially, will be subject to numerous limiting assumptions, many of which can be heroic and/or unspecified. Such a prediction-mode culture is intended to quantify the confidence in the effectiveness of the actions supported by 
the modeling and can be used to infer how uncertainty might be reduced. An alternative, however, is to embrace the less-probabilistic method of exploration of uncertainty.

\subsubsection{The way forward}

Addressing this grand challenge requires a paradigm shift towards integrated uncertainty assessment as a fundamental principle and standard practice for SES modeling. The most important principle that must become standard practice in SES modeling to overcome this challenge is that uncertainty types and sources need to be identified, prioritized and managed throughout the whole modeling process. Uncertainty assessment and its communication should not just be a technical add-on. Its consideration should begin at the problem defining stage, integrated into the workflow and involve all relevant stakeholders. Such management of uncertainty should be iterative throughout, revisiting objectives, assumptions and practices to discover feasible interventions (Fu et al., 2015). To realize this paradigm shift we identify below several priority areas for research and action.

More attention to the qualitative aspects of uncertainty. Uncertainty assessment demands more eclectic treatment in the SES context, some of it necessarily being more qualitative and empirical. Most SES modeling steps need expert and/or stakeholder engagement and evaluation, for which there is now much guidance regarding the why and how (e.g. Bert et al., 2014; Voinov and Bousquet, 2010; Walker et al., 2003; Zellner et al., 2012). Used wisely, stakeholder and expert engagement, in conjunction with documented workflow practices and modeling assumptions, can make uncertainties transparent and even reduce them. Another crucial, and largely qualitative, aspect for SES problems is well defining the problem scoping and framing, as well as taking into account the governance, societal and environmental contexts, and level of certainty required for the model purpose (see Hamilton et al., 2015 for integrated assessment and modeling; and Jakeman et al., 2016 with respect to integrated groundwater management). Research opportunities are still untapped for the use of methods (e.g. mental modeling, critical systems thinking) that explicitly articulate, critically analyze, and incorporate different problem frames into the modeling process (Quinn et al., 2017). All this requires thoughtful engagement with stakeholders and experts, and devoting more time and resources than often is allocated in projects.

More attention to methods that identify and integrate model structure sources of uncertainty. In the technical modeling phase, components representing the different sectors of an integrated SES model can have less standard, and different, formulations to one another, as well as varying levels of epistemic knowledge and data informativeness (e.g. some may be simple equations, others rules, some Bayesian networks or partial differential equations). These properties make standard methods of uncertainty analysis, such as those based on strict Bayesian techniques, unsuitable. Exploring uncertainty requires not only varying parameters, but also considering alternatives that relate to assumptions in model structure. The need to drastically simplify reality in SES models leads to potentially high structural uncertainties. Attention here is particularly relevant when there is uncertainty about behavioral characteristics of the social system, such as which decision heuristics the public uses (Janssen, 2016), or competing paradigms about any component, such as how to represent ecological response. One method to handle structural uncertainties where there are two or more competing hypotheses about system processes is developing and evaluating multiple model structures (Pollino et al. 2007; Wilensky and Rand, 2007). Another approach is having the model structure, including the underlying conceptual model and assumptions, reviewed by subject experts.

Beyond traditional quantitative methods. Uncertainty crosses boundaries and propagates among system components, and it can defy treatment, at least in part, by probabilistic methods. Traditional methods alone, such as Monte Carlo based approaches to a model, therefore, need to be complemented with a mix of approaches, especially when epistemic uncertainty means that the probability distributions from which to draw Monte-Carlo samples are themselves unknown (Ferson and Sentz, 2016). Algebraic, local and global sensitivity analysis, for example, can play a significant role in screening and ranking model influences and can be used as tools to put more emphasis on understanding the behavior of model components and their interactions. The methods listed in Table 1 are under-utilized in SES modeling, in particular the methods highlighted in the paragraphs below.

More attention to deep uncertainty and exploratory methods. If emphasizing possibilities rather than probabilities, exploratory modeling and analysis can be useful for searching for scenarios that lead to good, poor 
and intermediate outcomes, or specified objectives such as robustness metrics (Kwakkel and Pruyt, 2013; McPhail et al., 2018). Exploratory modeling and analysis is related to robust decision making where computerassisted reasoning is used as an adaptive decision-support tool for complex systems with "deep uncertainty" (Hoch et al. 2015; Lempert, 2002; Zellner et al., 2012). It implies a shift towards policy robustness, building on an understanding of uncertainty of trajectories and outcomes. In other words, uncertainty is not eliminated in this framework, but instead it is understood and incorporated into the decision-making process (e.g., Bankes et al., 2002; Zellner, 2008). These approaches are used in finance such as with bank "stress tests" which became widespread after the 2007-2009 global financial crisis, where hypothetical crises are determined and used to quantify the robustness of a banks' balance sheets. Scenario-based approaches, analogous to financial stress tests, are now being increasingly applied to decision-support studies under deep uncertainty (Trutnevyte et al., 2016; Guivarch et al., 2017).

More attention to surrogate modeling methods. Where components of models have prohibitive runtimes for analyzing uncertainty through multiple simulations, surrogate models or model emulation can be attractive. Various methods have been developed to produce simpler/surrogate versions of an expensive model, in order to simulate its response to uncertain model parameters and inputs (see Yang et al., 2018 for an example application). The main requirement for constructing a faster running surrogate is that the response surface of the expensive model is smooth. Some of the most popular surrogate types include polynomial chaos expansions (Sudret, 2008), Gaussian processes (Rasmussen and Williams, 2006), and sparse grids (Bungartz and Griebel, 2004). The most efficient are goal-oriented in nature and target very specific uncertainty measures. To our best knowledge, surrogate modeling is mostly used in environmental modeling, particularly hydrological modeling, but not for socio-economic systems. Surrogate modeling is thus a worthwhile direction for SES modelers to consider.

Better utilization of statistical data analysis techniques to inform uncertainty analysis. Almost always neglected or at least not reported is the analysis of data and its relationship to the model. There is a wealth of tools available to detect outliers, trends, implausible correlations, and timing errors in model responses, and to extract information from data. The value of simple visualization of model outputs in relation to model inputs, such as through their cross-correlation, is typically very useful before launching a sophisticated uncertainty analysis.

Strengthening the communication process among model developers and the audience. It is not only critical to characterize uncertainty, but also to draw on established best practices and communicate this effectively to decision makers. In practice, good communication of uncertainty can improve decision making by highlighting tradeoffs and enabling compromise seeking (Zellner et al., in press). It is important to incorporate all relevant views in the analysis to avoid gridlocks if decision makers are unhappy with the model results (Hoch et al., 2015). To address this interdisciplinary knowledge gap, modelers would benefit from working closely with social and behavioral scientists as well as data and computer scientists (e.g. visual analytics) to design and implement effective measures for communicating uncertainty sources and their effects on model simulations (Fischhoff, 2006; National Research Council, 2007).

\subsection{Grand challenge 3: Combining qualitative and quantitative methods and data sources}

\subsubsection{Nature of the challenge}

Integrating qualitative and quantitative data presents both challenges and opportunities to modeling SES. The physicist John Platt (1964) famously observed that "Many-perhaps most-of the great issues of science are qualitative, not quantitative, even in physics and chemistry." Nevertheless, qualitative data is often described as though it is inferior to quantitative data for modeling purposes, something to be settled for when it is impossible or impractical to acquire quantitative data (Smajgl and Barreteau, 2014). Such reluctance can arise from the perception that models derived from qualitative data are "vague and therefore difficult [...] to validate or falsify" (Di Baldassarre et al., 2015). On the other hand, qualitative data collected by social scientists, often in the form of narratives, offer in-depth perspectives on individuals and their interactions with the natural and social environment. Thus, qualitative data are referred to as 'thick data' to emphasize the quality they come with, which is especially in opposition to the current trend of over-valuing 'big data' (Wang, 2013). 
There are advantages to mixed-methods research, combining both qualitative and quantitative methods and data sources. Quantitative data can measure some attributes of a system, while qualitative data can provide insight into the reasons why those attributes change, i.e., the processes of change (Kline et al., 2017; Millington and Wainwright, 2017; Mingers, 2001). Mixed methods have proved valuable for modeling land use change, for example, with qualitative research providing rich descriptions of the heuristics employed by land-users to make decisions (Manson and Evans, 2007; Polhill et al., 2009). Mixed methods research can also provide opportunities for triangulation, in which data acquired by one method are compared against data acquired by different methods (Jick, 1979; Midgley et al., 2013). Yet, developing models that combine both qualitative and quantitative methods is challenging as outlined below.

Determining the right balance between quantitative and qualitative aspects of data collection and model building. For certain studies, narratives and qualitative assessments are better, and for others, detailed quantitative assessments may be more important (Robinson et al., 2007). The mixture of qualitative and quantitative methods may be determined by scientific considerations of what kinds of data would be most relevant to investigate the research questions, but could also be guided by practical considerations of the feasibility of implementing different methods, and by stakeholder needs and desires, as well as resource and expertise constraints. The scale, at which the study is focused, can also play a role in selecting and combining qualitative and quantitative data methods. For example, some qualitative methods, such as close reading of documents or transcribing and coding interviews and focus-group discussions, are too labor-intensive to be deployed broadly, whereas quantitative surveys can more easily be scaled up to cover a larger region. Conversely, qualitative descriptions of a region, obtained from maps or remote-sensing imagery, may be more practical than performing quantitative fieldwork and groundtruthing.

Implementing mixed-methods in practice. This remains a challenge, partly because much of the existing mixedmethods research on SES is complementary, rather than truly integrative (Cheong et al., 2011). Integration of empirical data with model output poses additional challenges, especially when there are quantitative and qualitative aspects to the model output (Sætra, 2017). This cannot be isolated from the absence of standard tools and methods for integrating data from diverse sources that spans spatial, temporal and social organizational scales (Section 2.4).

Disciplinary perceptions of methods and data. There are significant differences between and within disciplines in the training of mathematical and computational skills. Historic emphasis on quantification in science has led to the extreme view, held by some, that 'real science' requires mathematical formalisms. Perceptions of superiority of methods in general may hamper the inclusion of more qualitative approaches (i.e., those that do not rely exclusively on mathematical and computational skills) such as those used in many social sciences and humanities. This perception may also explain the disproportionately small amount of funding from governmental agencies for social sciences.

\subsubsection{The way forward}

Many of the ways forward in bridging epistemologies across disciplines described in Section 2.1.2 will also help to address the challenge of combining qualitative and quantitative methods and data sources, particularly advancing multi-method methodologies and tools. When integrating quantitative and qualitative methods, models and/or data, there also has to be a determination of whether the assumptions and underlying processes are matching, or at least compatible. Three other priority areas for research include:

Reflective and comparative studies to examine the effect of alternative designs. There are different forms for designing a multi-method approach (e.g. parallel, sequential). However, there is limited understanding of the implications of each methodological design on a study's results. There is a need for case study applications that allow for more visibility into, and comparison of, different design options across different SES modeling problems. Implementing such requires methodological support from empirical social science and ethnomethodology fields for studying modeling methodologies in situ. This requires consistent reporting standards and protocols that capture sufficient details about the modeling process.

Development of methods to support semantics mediation. As mentioned in Section 2.1.2, establishing common ontologies is key to coupling models, tools and data from different disciplines. Particularly as we move towards automated integration of data, methods and models, assimilation requires a semantic mediation mechanism. 
Various methods have been developed to couple quantitative variables, like CSDMS [Community Surface Dynamics Modelling System] Standard Names (Peckham, 2014) or CF [Climate and Forecast] Convention Standard Names (Lawrence Livermore National Laboratory, 2012), but these are mostly used within a single set of disciplines. Methods and data repositories that operate across social and environmental disciplines (e.g. https://seslibrary.asu.edu/) are needed. First of all, however, semantic vocabularies for the various disciplines need to be agreed upon and built to make semantic mediation possible. Once vocabularies are built, the level of accuracy of integration of quantitative and qualitative data has to be determined, which in most cases will depend upon the scientific research question. Scale is also an important aspect of semantic mediation, as Villa et al. (2017) pointed out: "scale is key to establishing meaning", as scale shifts determine semantic compatibility. For instance, a particular phenomenon, for example rainfall, can be seen as an event by a meteorologist and as a process by a hydrologist.

Focusing on qualitative outputs of models. Qualitative features of model outputs are sometimes of more interest than their quantitative features, for example: whether the level of a natural resource will increase or decrease, whether a tipping point (of social or ecological origin) is about to be reached (see section 2.5.1), or whether a collapse in the level of natural resource is irreversible. In appropriate situations, recognizing that quantitative outputs are of less interest can lead to the use and continued development of methods that are less reliant on quantitative data. For example, while sometimes used only as a tool for communication or an intermediate step in model-building, causal loop diagrams are models based on qualitative data about causal relationships in an SES that can be analyzed to anticipate responses to leverage points (Luvuno et al., 2018). If the stability, or lack thereof, of an SES is the major output of interest, then the method of generalized modeling (Lade \& Niiranen, 2017) is an alternative to a fully parameterized simulation model that requires only semi-quantitative inputs easily derived from qualitative narratives.

\subsection{Grand challenge 4: Dealing with scales and scaling}

\subsubsection{Nature of the challenge}

Socio-environmental systems operate across a variety of spatial, temporal and organizational scales (Levin, 1992). SES models vary in spatial (from $\mathrm{m}^{2}$ to entire continents or global) and temporal coverage (from minutes to decades) and in levels on the social dimension (e.g. household and firms, to community, province/state and nation) (Figure 2). Modeling of such complex, multi-scale systems requires clarity on the representation of scales in each type of subsystem, and matching a conceptual representation of variables and processes with their data (Scholes et al., 2013; Robinson et al., 2018). Furthermore, since spatial and temporal domains between social and environmental systems tend not to overlap, they need to be coherently matched to allow for coupled modeling (Gibson et al., 2000). This matching often requires advancements in upscaling and downscaling methods of connected subsystems (Contreras et al., 2018; Poggio et al., 2018). Finally, macroscopic patterns and phenomena observed at higher scales in complex SES are an emergent result of microscopic behavior and interactions at lower scales (Epstein and Axtell, 1996; Levin et al., 2013). We discuss the essence of the issues associated with this grand challenge below.

Representing and matching scales in SES models. It is self-evident that the choice of a model's spatial and/or temporal resolution has a significant impact on the simulation results. Thus the discretization of a partial differential equation for representing a groundwater model, for instance, affects the model parameters and outputs produced. Likewise, in representing social processes, the choice of the time horizon and the length of a single time step would significantly affect results (e.g., the output of a social cost-benefit analysis; Trenholm et al., 2013). The choice of scale representation is further complicated when models with spatio-temporal mismatch are coupled (Vermaat et al., 2005; Wilson et al., 1999). For example, social subsystem models are often simplified to annual or seasonal temporal resolutions that differ from the representation of environmental subsystems which are often daily or even sub-daily (e.g., global dynamic vegetation models that use hourly temperature and precipitation data) (Evans et al., 2013). Models of human behavior are often designed for the individual or small group scale while many environmental problems are global in nature (Lippe et al., 2019).

In addition to the need for conceptual consistency, empirical models of coupled SES require downscaling and upscaling of social and environmental processes to match other subsystems within the model (Figure 2). In the literature, there are examples that demonstrate approaches to resolving these scale differences while 
maintaining ontological and process consistency between coupled models that representing SES (Robinson et al. 2018). While up/down-scaling approaches are actively used in environmental system analysis (Fowler et al., 2007; van Ittersum et al., 2013; Vereecken et al., 2007; Winsemius et al., 2013), they are in their infancy for social systems.

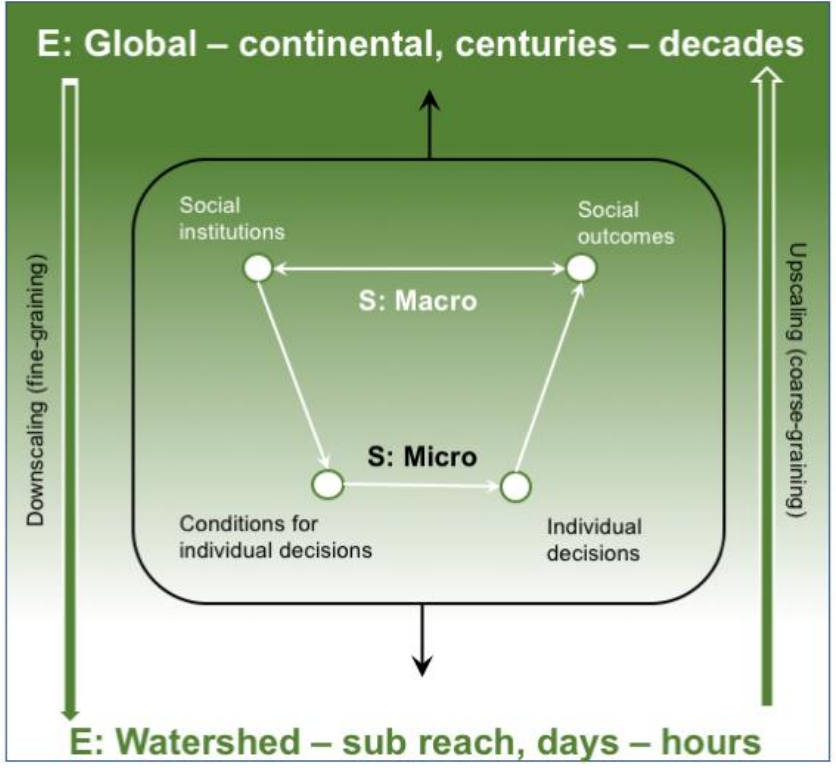

Figure 2: Scales and scaling in SES: a multi-scale social (S) subsystem is embedded in the environmental (E) subsystem that has a continuum of scales. The representation of scales in the social subsystem mimics the Coleman boat (adapted from Coleman, 1998).

Different levels of knowledge and data about the social and environmental subsystems at various scales. Ultimately, data availability drives what is to be represented in a social or environmental sub-model, and at what scale. Often empirical social and environmental data are collected through field sampling (e.g., household or fieldplot surveys) that may not represent the level of heterogeneity present across large spatial - regional, national or continental - scales. In contrast, the use and disaggregation of census data, or perhaps remote sensing data for environmental subsystems, assumes the group (or pixel) values are representative of the individual's (ecological fallacy), which is at best an approximation. Some environmental data has a long history of observation, often enabled by automatic sensors delivering high resolution data. Yet, high resolution social data usually represent a single time interval, such as a survey or a post on social media, since social panel data is expensive to collect and may be hindered by privacy issues. Furthermore, it is difficult to capture the mechanisms driving social change, beyond stated or revealed preferences or attributes. Hence, often it is possible to quantify the stock of human capital, assets and other materials but it is difficult to represent the process of change associated with the social subsystem. In contrast, it is often difficult to quantify stocks in the natural system (e.g., soil organic carbon) but we have a depth of information about how these may change over time (e.g., loss of soil organic carbon through cultivation).

Modeling phenomena across multiple scales. Development of models capable of tracing the evolution of phenomena across scales in coupled SES is rooted in Complexity Science, whereby the overarching paradigm is that macro patterns are an emergent result of heterogeneous behaviors and interactions taking place at micro scales (Epstein and Axtell, 1996; Farmer et al., 2015; Levin et al., 2013). In social systems, such cross-scale feedbacks - often presented as a Coleman boat (Coleman, 1998) - and the related aggregation problem (Kirman, 1992; Forni and Lippi, 1997) have long been a 'holy grail' for scientists. Coleman (1998) sought to explain how macro institutions (markets, social norms, voting rules) create boundary conditions for micro-actions of individuals (households, farmers, organizations) who in turn shape the former (Figure 2). However, which social scale is to be matched with a particular environmental scale is contingent on an empirical research problem and this choice is difficult since social components may shift along the gradient of environmental scales (Figure 2, dark green for macro scales to white for micro scales in the environmental subsystem). In SES modeling, a representation of generic cross-scale feedbacks that are broadly applicable among SES, and that directly affect 
our ability to replicate real-world SES outcomes, do not exist. Depending on the research question, cross-scale feedbacks could be either within the social sub-system (e.g. individual farmer decision $\Leftrightarrow$ national agricultural subsidy $\Leftrightarrow$ world food prices) or the environmental subsystem (e.g. local precipitation $\Leftrightarrow$ regional climate $\Leftrightarrow$ global climate model) subsystems, or within a coupled SES framework. While the former two seem to be the norm, there is no constraint on the number of levels of representation in multi-scale systems. Going beyond two scales requires modeling not only within both major systems (i.e., social and environmental within the coupled $\mathrm{SES})$, but also interactions among their subsystems.

\subsubsection{The way forward}

This grand challenge calls for SES models that trace phenomena across scales instead of focusing on one, and demands an explicit representation of cross-scale feedbacks. Advancing the following priority areas of research will enable appropriate representation of scales and cross-scale dynamics in SES modeling.

Evaluation and comparison of different methodological choices related to scale. Progress in SES modeling will benefit from formal tests and comparisons on the methodological choices (representing, matching, and aggregating scales). This must embrace choices related to the treatment of scale (space, time, organizational) in order to quantify the range of outcomes resulting from different coupling designs. Candidate issues warranting investigation in this respect are: how the use of different down/up-scaling methods influence the model's results and uncertainty; eliciting whether there are thresholds in this aggregation process that alter dynamics of a coupled SES model; and what conceptual reasons underpin those thresholds. Accumulating knowledge on these issues over time, through synthesis and comparison across multiple modeling applications and studies, should ultimately lead to more formal use of existing (and the development of new) analysis tools that act on model results and data arrayed on space-time-organizational cubes, thereby improving our representation and understanding of changes in processes across scales.

Developing accessible resources on scaling methods. Statistical and related methods exist that can be used for: estimating missing data across space or time (e.g., Kriging); upscaling, downscaling, or scaling out (extrapolating) input or model output data; and calibrating and validating across space and time. These methods however, are underutilized in SES modeling, suggesting that specialized tutorials and a community forum to foster the fusion of data at multiple scales to enable credible models, especially in data-poor environments, is needed. Appropriate scaling of SES models to provide relevant representation of the human dimension is vital to assist actionable science in the Anthropocene era that we are witnessing.

Using social models at different scales to represent the vertical interactions within the social subsystem and cross-scale processes in SES. Acknowledging that various societal processes occur at different scales demands representing them hierarchically (farmer, household, firm, city, region, country, world economy). Future crossscale SES models are likely to be a nested integration of different software components and model types (Belete et al., 2017b; Verburg et al., 2016), or a modular approach with validated, theoretically-grounded decision modules representing various social actors combined within one software platform (Bell et al., 2015). Best practice in SES modeling advises that combining distinct models could utilize software wrappers to link models (Belete et al , 2019) and should entail full detailing of how human and environmental processes are intertwined (Belete et al., 2017a; Rounsevell, et al., 2016).

\subsection{Grand challenge 5: Capturing systemic changes in SES}

\subsubsection{Nature of the challenge}

SES are constantly in dynamic flux. These dynamics are of dual nature. Often trends can be observed in dynamics where gradual changes in past behavior or processes of a system could be extrapolated into the future with some confidence. Yet, an important characteristic of SES is its inclusion of non-linear spatio-temporal dynamics, especially for addressing unexpected systemic shifts to a new regime (Scheffer and Carpenter, 2003; Scheffer, 2009). A number of closely related phenomena - tipping points, regime shifts, non-marginal changes, structural changes, systemic shocks, critical transitions, socio-techincal transitions, bifurcations (de Haan and Rotmans, 2018; Lamberson and Page, 2012; Scheffer, 2009; van Nes et al., 2016) - describe these non-linear changes that are substantial and often sudden and irreversable. Such systemic changes are well-documented worldwide (see the Regime Shift database: https://www.regimeshifts.org, including examples of lake eutrophication, desertification, and overfishing). Regime shifts in socio-economic systems are also common, e.g. changes in 
political regimes, institutionalization of new rules, disruptive technologies and financial crises and market bubbles.

Our ability to capture such transitions using quantitative models is fundamental to developing a better understanding of the key processes and their interactions and variability within SES dynamics. Existing modeling approaches, commonly used to capture and model systemic changes, include statistical models, equation-based system dynamics modeling and agent-based modeling (Filatova et al. 2016). Two fundamental issues still perplex modelers of systemic change in SES:

Lack of knowledge and data on the fundamental processes that drive systemic shifts in social systems. A key barrier is the lack of a coherent and consolidated body of knowledge about the causes and dynamics of systemic changes in social systems that is on par with that of natural systems. This includes data gaps where longitudinal socio-economic and ethnographic data are not consistently measured over time or between cases, which continues to hamper our ability to create and validate models of SES dynamics. Several large social, economic and ethnographic datasets remain underexplored for trends and possible drivers of change (e.g., Ullah et al., 2015), such as the World Values Survey (http://www.worldvaluessurvey.org/wvs.jsp), the Standard Cross Cultural Sample (http://intersci.ss.uci.edu/wiki/index.php/SCCS), the Human Area Relations Files (http://hraf.yale.edu/), PREP open dataset (https://www.prepdata.org/), and the Demographic and Health Surveys (https://www.dhsprogram.com/); although there are some good recent examples of this (e.g., CastillaRho et al., 2017). While much natural science data are currently compiled into global open access datasets (e.g., ORNL NPP, https://daac.ornl.gov/cgi-bin/dataset_lister.pl?p=13), there are barriers for doing this with socioeconomic data including privacy concerns, the cost or effort of data collection, or inconsistency in measurements of the same phenomena and variables due, for instance, to disciplinary divides (Section 2.2).

Limited methods for modeling systemic changes. SES models are still challenged by relying on past data from multiple sources (see Section 2.3), and then deriving model architectures (i.e. combinations of modeling formalisms and code). Yet, the structure and feedbacks of SES are affected under systemic changes (e.g. during transformations, Moore et al., 2014), demanding an introduction of new variables or causal linkages in formal models. Despite recent progress, current modeling methods exhibit limitations by pre-defining the model entities, rule or equations that guide their dynamics and determine the direction of feedbacks (Filatova et al. 2016). Drawing generalizations from historical case studies in an era of unprecedented climate change and planetary-scale anthropogenic pressures on the environment, coinciding with a boost of new technologies raises uncertainty about the appropriateness of models that hardwire coupled social and environmental processes into SES models.

\subsubsection{The way forward}

Three key areas of research need addressing to advance our understanding of the causes and dynamics of structural changes in SES and our ability to capture them:

Improving knowledge and data for social systems. We need to work towards enhancing the state of knowledge about the causes and dynamics of structural changes in social systems. Knowledge is not on par with that of natural systems and may never be, but there is considerable scope for its enhancement. Moreover, global datasets of socio-economic data beyond the standard census type (surveys, ethnographic work, field and lab experiments) are deeply needed to meet the challenge of understanding unexpected change in SES. As mentioned above, cost and privacy issues often limits extensive social data collection and sharing (Thakuriah et al. 2016), in addition to interpretation (see Section 2.3 for a related discussion of combining qualitative and quantitative data).

New methods for reasoning about and modeling systemic change. Development and testing of methods that model changes in the SES structure are needed. Evolutionary mechanisms and other Al methods or narratives and visions derived in participatory contexts, could enable the generation of new formal or informal rules (Table 3). Alternatively, adaptive network models (Sayama et al., 2013) could bring the structural focus of network modelling into models of SES dynamics. Better methods for identifying critical transitions or regime shifts in model output, including an automatic creation of "stability landscapes" (Bitterman and Bennett, 2016) and statistical methods of regime shift identification (Filatova et al., 2016) are needed. Very often sparse data needs to be used simultaneously to calibrate and validate the model. Retrodictive (or abductive) methods offer a 
promising path around this paradox because model structure can be derived from theory, rather than from data only (Mingers, 2006). However, it is important to ensure that model results are meaningful and can be connected to real cases in relevant ways.

Dealing with uncertainty issues as they relate to systemic change. It is especially pertinent to identify sources of uncertainty, and to be able to differentiate unexpected changes due to modeling errors from those that are novel emergent behaviors of the modeled system. It calls for developing methods that trace the main sources of influence over specific system state transitions in SES model output, often prone to multiple sources of influence. Issues of model identifiability (sometimes known loosely as equifinality and multifinality of model instances) are likely to be enhanced in coupled SES, as will be the uncertainty arising from "unknown unknowns" related to omitting, among other things, regime shifts that were not anticipated. Recording the temporal dynamics of SES models should entail traces of underlying processes driving it, to enhance our understanding of how and why a model run evolved. Moreover, new validation methods need to be embraced that extend beyond historical data, to test validity of processes that have not yet occurred but could. Gamification, choice experiments, expert visions, and narratives about possible futures (or alternative past) from participatory research may create an empirical basis for testing whether emergent states in SES models are feasible. Some of these validation methods need to account for, not only system-level transitions, but also micro-level, to capture spatially-explicit changes (Bone et al. 2013; Brown et al. 2005) or social interactions. These considerations emphasize the need to test alternative hypotheses, using multiple techniques of which exploratory modeling and analysis (discussed in Section 2.2.2) is a central element. Unknown unknowns and Black Swan events (Taleb, 2007) are somewhat more difficult to incorporate, but models should include processes to allow an emergence of low-probability scenarios, especially given that stochastic tails may get 'fatter' (e.g. high-end climate change scenarios).

\subsection{Grand challenge 6: Integrating the human dimension}

\subsubsection{Nature of the challenge}

A spectrum of SES models ranges from those that represent underlying natural processes well but neglect the role of people, organizations and institutions, to those that are rich in representations of social processes but fail to do justice to the environmental dimensions of the problem. Bidirectional feedbacks between the human and natural model subsystems, however, are paramount to reproducing the non-linear dynamics of SES (Filatova et al., 2016; Robinson et al., 2018; Schlüter et al., 2014). This implies that the mechanisms driving dynamics within each subsystem should be captured in complexity that is sufficient, but at the same time is warranted by the modeling purpose.

Contemporary quantitative SES models used for policy support are dominated by three common approaches in representing the human dimension: scenarios, statistical models and equilibrium models (columns i to iii in Table 2). These three approaches are convenient because they are formal and avoid qualitative concepts. By assuming that the decisions of a rational representative individual can be directly scaled up, they also conveniently "solve" the conceptual issue of how to model economic behavior and how societies make choices. This ability to aggregate behavior is especially important for coupled SES models, which often operate over regional, national, continental and global scales. Yet, in some cases, this stylized scaling up of human behavior can be unsatisfactory because it does not allow for capturing sufficient heterogeneity and therefore could have misleading consequences for the design of environmental policies (Farmer and Foley, 2009; Pindyck, 2013; Stern, 2016).

Hence, over the past decade a rise of alternative modeling formalisms have occurred, driven by the urge to go beyond the static representative, by developing rational agents with perfect information. These approaches emphasize the use of heterogeneous actors (households, farmers, firms, cities, regions, etc.) who may be boundedly rational and experience an asymmetry of information. Formalisms such as agent based models represent social behavior more fully, as do interactive approaches where individuals and representatives of organizations and institutions take decisions related to the human dimension in SES (columns iv to vi in Table 2). As the examples in Table 2 illustrate, the six alternative methods to represent human dimensions in SES vary in their abilities to accommodate feedbacks with the environment, diversity of social decisions, interactions and learning within the human dimension, and their richness of theoretical foundations. When present, these come at the price of higher data intensity, time and costs to acquire quantitative and qualitative social data, technical modeling skills and an extended uncertainty analysis (as described in the challenges above). Yet, the benefits of 


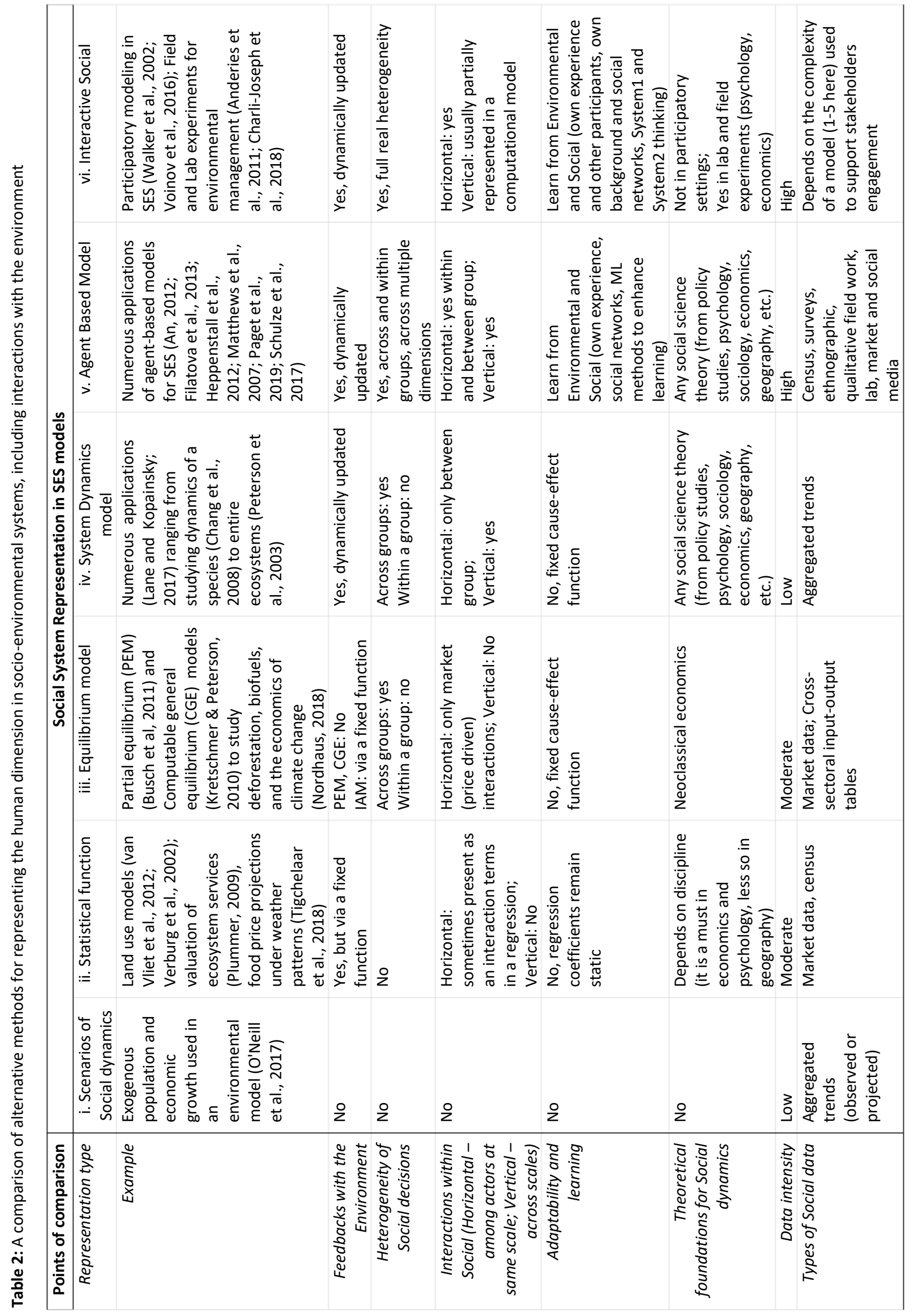


this evolution in methods are evident when, for example, 'Scenarios' of how the human dimension develop in SES with agent-based approaches are compared (Table 2). With no feedbacks between the modeled dynamics of an environmental subsystem and the fixed social trend in 'Scenario' approach, the modeling may produce impossible or illogical results, such as continued exponential population growth after environmental destruction (Dellink et al., 2017). Instead, in agent-based models and systems dynamics models, for example, time lags and feedbacks can be represented with modeled agents adjusting their decisions according to conditions (Bell et al., 2019; Bonabeau, 2002; Zellner, 2008). Policy choice on SES management stemming from these two different approaches would differ substantially, potentially overlooking or over-predicting an SES collapse.

Social science (sub)models fall behind for several reasons including the following:

Limited funding for social science. Funding allocated for social science modeling has historically been much less than that for natural science modeling (for example US National Science Foundation budget for social, behavioral and economic sciences is $4 \%$ of the total research funding budget). This may explain why only a small subclass of social sciences (e.g. environmental economics, environmental psychology, environmental planning and policy, sometimes anthropology) consider environmental challenges as a subject of research.

Inherent difficulties in gathering data and representing the process of actual decision-making in models. SES modelers often access the outcomes of decision making (e.g., revealed preferences) or indirect representations (e.g., stated preferences), but not the decision process itself. As a result, the human behavior incorporated in coupled SES models is often rudimentary compared to the state of the art in social science modeling, and as such out of touch with current social theory. Recent reviews on approaches to represent the social dimension in SES models discuss this problem in detail (Müller-Hansen et al., 2017; Schlüter et al., 2017).

\subsubsection{The way forward}

Despite being at the core of SES models, to date the representation of the human dimension has, by and large, been inadequate. Achieving appropriate representation of the human dimension in SES models, including social behavior, behavioral dynamics and interactions with the environment, at relevant scales, requires development in the following areas.

Better alignment between theory and data that inform social decision rules. This alignment is required to find ways to specify human dimensions in coupled SES models. Cases where a relevant social theory have been empirically validated and can be used 'off the shelf' are rare. Often, broad outlines of relevant human behavior are understood but parameters specific to the situation are unknown and require contextual (quantitative and qualitative) data to specify rules of socio-economic decisions, learning and interactions. Model parametrization raises questions about the extent to which available data are valid for representing the phenomenon of interest.

Socio-economic data are being gathered in increasingly large quantities, opening possibilities to validate (or reject) nuanced social science theories relevant for environmental decisions. The rise of 'big data' and wide use of machine learning algorithms (Tolk, 2015) could help in building better empirical models of human behavior. Currently, there are only a few examples (Elbattah, 2018) of this approach but the increasing amount of data availability and growing computational power suggest this will be an active and rapidly expanding area in the nearby future. At the very least, machine learning algorithms should provide some heuristics about social decisions rather than being implemented as black boxes.

Going beyond ad hoc assumptions or stylized theories underpinning human behavior. The social science should progress beyond modeling farmers and households, to represent firms and organizations that often alter SES dynamics more than individuals. Institutions - formal ones such as markets and informal ones such as norms are major vehicles driving dynamics in human dimensions of SES. Yet, it is not sufficient to duplicate the same agents (e.g. people) to produce dynamics typical for a group-agent (e.g. organizations or firms) or an agent representing processes at another scale (e.g. government, policy institution or a city). Acknowledging that various societal processes occur at different scales demands the use of different social models (farmer, household, firm $\Rightarrow$ city $\Rightarrow$ region $\Rightarrow$ country $\Rightarrow$ world economy) to represent them, an area which directly links to necessary development in scaling issues (discussed in Section 2.4.2). Capturing behavior - and especially behavioral changes - calls for new coupled models with the ability to sufficiently capture descriptive decision representations of individuals, farmers and households, as well as the organizations and institutions they 
collectively form, to allow for adequate assessment of impacts, which makes models more relevant to their users (Beckage et al., 2018; Gilligan, 2018).

Converging on a set of generic modules to represent iconic socio-economic decisions in the environmental context. Less funding for social sciences and the nature of research in SES, which is often case study based, makes it almost impossible to generalize findings and excel in this discipline. There is potential for fundamental progress with increased effort in a number of key directions:

- focusing on the same geographic areas or types of SES problem to leverage shared data and network (e.g. EU COST action http://www.cost.eu/ or Coupled Natural and Human Systems of the National Science Foundation),

- $\quad$ providing individual incentives for contributors of code and data (See Section 2.1.2), and

- creating an open access library of shareable human decision code components (e.g. https://www.CoMSES.net/). This will help the SES community to build upon a formal representation of iconic human decisions in code that is already verified (and potentially theoretically grounded and validated for a particular context) and allow further improvements instead of reinventing the wheel.

\subsection{Challenge 7: Elevating the adoption of SES models and impacts on policy}

\subsubsection{Nature of the challenge}

A low uptake of SES models in policy design and implementation is a well-recognized problem (Zellner and Campbell, 2015). This problem refers to the gap between model development and the actual use of models to support collaborative decision making, which is common to environmental modeling (Voinov and Bousquet, 2010). Increasing the complexity of an SES modeling exercise to address this gap comes at costs; for example, of (dis)agreeing upon the greater number of assumptions, the interpretation of modeling results, and the prioritization of both social and environmental goals. Even when stakeholders have the opportunity to engage in the modeling process, power imbalances and mismatches between the locus of the decision and the scale of modeling can pose significant obstacles to informed, equitable, and empowered decision making. This is a deep and common challenge that manifests the more fundamental problem about the use of multiple sources of knowledge to support decision making in the face of complexity and uncertainty (Brooks, 1984; Jasanoff, 2003; Kasprzyk et al., 2013; Lempert et al., 2002).

Participatory modeling (PM) is a powerful approach to address SES-related problems, by harnessing the innovative capacity of diverse stakeholders to generate both understanding and novel solutions built on this understanding, and thus strengthening the adaptive capacity of SES. PM involves purpose and learning towards action, eliciting overt and tacit knowledge to formalize collective representations (models) of complex problems, and co-generating new insights to advance policy. In addition to innovation, PM promotes a sense of ownership or appropriation, not only of the problem, but also of the analysis and findings that are brought forth through an open and transparent discussion of model assumptions and tradeoffs (Sterling et al., 2019). This rapidly coalescing field is a testament to its promise. Nevertheless, decision makers who would greatly benefit from using models of socio-environmental interactions and feedback to inform their actions, are unlikely to be trained SES modelers. Progress in this respect involves balancing the relevant representation of complex SES with the ability to effectively communicate and incorporate such complexity within the decision-making process, to then lead to policies and actions that improve both social and environmental outcomes. We identify several challenges to be addressed in this effort:

Measuring the impact of SES modeling on decision making. Methods and theories from learning sciences have introduced new ways of designing PM exercises, and investigating the impact of PM on learning and decisionmaking (Mallavarapu et al., 2015; Milz et al., 2017: Radinsky et al., 2017). Anthropological techniques that map a group's set of cultural models are also being adapted for this purpose. But how such learning is tied to actions, and system transformation from these actions, remains hard to establish and assess.

Lack of understanding of the inevitable uncertainty that is part of modeling complex SES. The limited adoption and influence of SES models is partly due to the relatively poor understanding by both modelers and decision makers of the various sources and kinds of uncertainty, and how to incorporate this in a decision-making context (see Section 2.2). In addition to improving knowledge, it is important that there is a shift from a need for accuracy 
(i.e., forecasting the future) to an acceptance of robustness as a sound policy strategy. The acceptance of robustness could involve anticipating a range of possible futures that are more likely to capture system behavior, and where policy can be designed to address the distribution of outcomes (Bankes et al., 2002). In Section 2.2, we have articulated various ways for more explicit incorporation of uncertainty management in the development of policy around SES. The possible consequences of complex SES dynamics, such as irreversible regime shifts (see section 2.5 ), is also poorly recognized by some policy makers.

Scaling up of outcomes from participatory modeling across multiple scales. PM can be very effective and productive in small participatory settings. However, SES-related problems involve cross-scale processes, and thus require scaling up beyond in-person interaction, to include a broader representation of systems, knowledge and values. Platforms (modeling tool frameworks, and interfaces and facilitation structures to support their use) must be developed to enhance the exploration of the complex SES problem space, the design of possible solutions, and the evaluation of inevitable tradeoffs that arise from implementing such solutions. Such platforms would be better able to sustain the level and diversity of engagement needed to encourage meaningful discussions and advance policy development and transformations in SES modeling. Preliminary work (e.g.: participatorymodeling.org) has shown the promise of such platforms in enhancing individual and collaborative learning about SES complexity, in designing innovative and effective solutions to complex SES problems, and in reaching compromises around solutions. This work is in its infancy, however, and is hard to scale up in its current form.

\subsubsection{The way forward}

To bridge the gap between SES model development and its use in practice, particularly in decision- and policymaking, we suggest addressing the following research opportunities:

In-depth understanding of participatory modeling aspects. We should seek to gain more in-depth understanding of the process by which to enhance access to modeling by novice stakeholders. How and when is it appropriate to engage them? How should we assess the engagement and the outcomes of the modeling exercise? Research is underway, but more is needed to help define the right level of abstraction for different problems and stakeholders, and to understand how stakeholders use such models and their results. We seek to develop generalizable guidelines for selection of appropriate modeling practices and tools (Voinov et al., 2018), whilst understanding where tailoring to specific contexts is needed, particularly with respect to the inclusion of cultural differences in stakeholder engagement, and in linking international science and local level sustainability efforts (Lahsen and Nobre, 2007). While some efforts are underway (Gray et al., 2018; Jordan et al., 2018; Sterling et al., 2019), this is still an active and crucial area for further research. Ethical considerations must be part of this endeavor, as both tools and processes are vulnerable (inevitably) to substantial manipulation, but they can be transparent and even productive if power imbalances are recognized and neutralized.

Better understanding of the political process underpinning decision making. It is imperative to know where models and other decision support tools and sources of evidence fit within the political spectrum (Lempert, 2002; Parker et al., 2015). And this in turn requires understanding of the judgment process (Hoch et al., 2015; Zellner et al., 2012), the role that mental models play in shaping collective judgments (Milz, 2015) and how various models (e.g. types, outputs) can be effectively used to inform mental models. For example, heterogeneous beliefs and values, together with outcome distributions, can be more effectively addressed with ensembles of models and the wisdom of crowds than with single comprehensive models aiming to produce accurate predictions (Bankes et al., 2002; Zellner, 2008). Building this knowledge also has the potential to improve how the human dimension is incorporated in SES models (See Section 2.6).

More effective visualization. New methods and data should include those that help convey the social and biophysical complexity of SES and the tradeoffs that arise from possible solutions to addressing SES-related problems (Zellner et al., in press). Effective visualizations of model outputs or information, tailored to the audience including decision makers, ensures better, actionable understanding of the problem (Grainger et al., 2016). New kinds of interactive interfaces are also needed to help stakeholders access models, be it to make sense of simulation results (e.g. through monetization of values or other forms of impact representation), to shape assumptions and inputs in model development and scenario building, and to actively negotiate around inevitable conflicts and tradeoffs. The role of stakeholders should be much more expansive than a passive 
audience that consumes information from experts, and rather is a co-creator of models, knowledge and solutions.

\subsection{Grand challenge 8: Leveraging new data types and sources}

\subsubsection{Nature of the challenge}

We live in an era where data become rapidly available due to technological advances in sensory devices and computational infrastructures for archiving and sharing information. The inflationary epoch of data explosion is also referred to as the "Data Big Bang" (Pesenson et al., 2010). New data sources relevant for SES modeling include non-traditional sources of socio-environmental data. Blazquez and Domenech (2018) identify six categories of socio-economic big data sources that generate data, actively or passively, when individuals use search engines, social media, mobile devices, apps, social networks, or wearable devices. All these contribute to an ever-increasing digital footprint of individuals, which can be upscaled to social institutes. These technological developments include:

- The proliferation of new platforms such as CubeSats and drones (Chin et al., 2008). Sensors and analytical tools are rapidly expanding the use of remotely sensed and other data in studying social and socio-environmental systems (e.g. Bayat et al., 2017).

- Mobile devices and social media postings offer large quantities of (geolocated) data, which can be mined as new sources of information, to derive new insights into socio-environmental processes. Some application areas include tracking human mobility and migration (Kryvasheyeu et al., 2016), smart tourism (Brandt et al., 2017) and visitor tracking (Tenkanen et al., 2017), landscape valuation at continental scales (van Zanten et al., 2016), and disaster response (Chen et al., 2016).

- The widespread penetration of smartphones and inexpensive internet-connected sensors (Internet of Things; Fang et al., 2014) is enabling crowdsourcing of data gathering and enabling citizens and communities to take active roles in citizen science (e.g. Certomà et al., 2015; Jiang et al., 2018; Muller et al., 2015).

- Advances in big-data processing and machine learning are making it feasible to process ever-greater quantities of data, and cope with the diversity of data sources in the environmental sciences (Lokers et al., 2016).

- It is becoming increasingly feasible to model large and complex systems (Mattman, 2013), including agent-based simulations comprising many millions of agents (Abar et al., 2017; Melgar et al., 2014) or machine learning methods for data-driven modeling (Willcock et al., 2018).

Methods have emerged to synthesize heterogeneous data from multiple sources to support holistic analyses and extraction of new knowledge (Gibert et al., 2018). New data sources are particularly relevant for policy making in the context of citizen science, as an integral component of public participation in policy in e.g. Europe (Schade et al., 2017), but also for monitoring Sustainable Development Goals, a research direction that the United Nations Global Pulse is exploring. Global Pulse is an innovation initiative of the United Nations working to harness big data, artificial intelligence and other emerging technologies to support sustainable development and humanitarian action (UN Global Pulse, 2017a), as in the case where data is used from social media as evidence for understanding movements and perceptions of migrants in Europe (UN Global Pulse, 2017b).

New innovative technologies for analyzing and visualizing data offer great promise to take advantage of this data increase to address the challenges and opportunities for SES modeling as outlined in this paper. However, these advantages bring their own challenges for SES modeling. The most prominent example relates to harvesting social datasets that are currently sparse (See Section 2.4 and 2.5). With new data types and sources (social media, mobile devices), social datasets will be enriched. The challenge for SES modeling is to include the abundance of data from new sources in their portfolio, and combine these with traditional information in order to improve decision making. This challenge extends to ways to address the issues of privacy, uncertainty, and upscaling.

Dealing with emerging ethical issues. The flipside of the ability to capture individual data is the inevitable privacy issues, such as breaches and risks. For example, it has come as a shock to many social and medical scientists to discover that machine learning methods can partially or completely re-identify individual subjects from data that was believed to have been de-identified sufficiently to be safe for public release (Kitchin, 2013; loannidis, 2013; 
Mai, 2016; Maliapen, 2009; Rothstein, 2010). This introduces important ethical obligations for researchers to protect respondents' privacy. These may also affect the availability of data for research purposes if data sources that are currently publicly available, such as municipal open-data portals, become unavailable due to privacy concerns. Moreover, social-media providers sometimes make detailed microdata available to researchers or collaborate with researchers to conduct experiments, but many questions arise about the ethical oversight of such experiments and data collection, access to data for replication studies, and the potential conflict of interest between sound research and the business interests of social-media companies (Farrell, 2017; Rosenberg et al., 2018). There are however privacy-preserving methods for computing participatory mapping using mobile phones, as in the case of noise pollution (Drosatos et al., 2012; 2014).

Methodological issues around data collection and use. The availability of large amounts of data should not blind us from sighting fundamental scientific questions about the data collection methodology, and the computability of the underpinning methodological principles with the study's purpose. For example, social media and mobile phone signals can provide data on locations and movements of millions of people, but do not generally constitute a representative sample of the population (Barberá and Rivero, 2015; Weeg et al., 2015) nor perhaps directly meet the main SES issue in question. Similarly for environmental data collected by inexpensive sensors, which can be valuable (Samourkasidis and Athanasiadis, 2016), it is important to understand and account for challenges in calibration and drift. Finally, modeling tools, especially those that are data intensive, can easily become too obscure to be useful in an open and transparent deliberative decision-making process. Such processes are the kind that are most needed to effectively address SES challenges, since action to address these challenges must typically be coordinated across multiple actors operating at diverse temporal and spatial scales (Zellner and Campbell, 2015).

\subsubsection{The way forward}

For SES modeling to benefit from promising technological advances such as new data types and sources in SES modeling, the associated ethical and methodological dilemmas need to be overcome.

Incorporating ethics and equity considerations. Both researchers and institutional review boards need to be familiar with the ethics of data science and big data and must keep abreast of new developments in this area. Ethics of data science must be incorporated into responsible conduct of research training. Questions of power, representation, and equitable access arise: researchers should consider whether data-collection and analysis methods are likely to exacerbate inequalities through biased data collection, biased analysis, or presentation of results in ways that exclude certain groups (e.g., technical presentations that are difficult to understand without advanced education) (Lum, 2017; Lum and Isaac, 2016; O’Neil, 2016).

Addressing biases and uncertainty. Where social media or other sources of large-scale non-representative data are used, tools such as multilevel regression with post-stratification are valuable for addressing selection and sampling biases if sufficient demographic data are available (Howe and Leiserowitz, 2013; Wang et al., 2015; Weeg et al., 2015; Zhang et al., 2015). A key principle to consider is what value any source of big data will add to resolving an SES problem and if that data reduces uncertainty (Section 2.2.2) in the modeling. It cannot be assumed that more data will reduce uncertainty, as the nature of uncertainty can simply change. However, big data can help better characterize and bound uncertainty for variables that do not experience a regime shift over time.

\section{Synthesis and conclusions}

In this section, a vision is synthesized for the future of SES modeling, and priority areas for research and action. The vision is organized around harnessing the following opportunities: education and training; consolidating methodological knowledge through multiple and comparative studies; and shifting from piecemeal and ad-hoc uncertainty assessment practices to integrated uncertainty management. If these issues can be surmounted, then we can ensure that decision makers have tools that can better address their needs. 


\subsection{Education and training}

As mentioned above, it can be challenging for scholars to have sufficient disciplinary training among all relevant disciplines to be literate in the broad topics of SES modeling. SES scholars must master integration and be able to bridge diverse epistemologies. In order to facilitate education of the future generations of SES modelers, we need to:

- Emphasize collaboration between disciplines with proper communication, knowledge sharing and documentation skills. This includes SES modelers developing standards and protocols on exchange of data and model code, learning to collaborate effectively in online environments, and being proficient in using versioning systems like Git and hosting services like GitHub to enable collaborative modeling.

- Provide open access to more training opportunities online (tutorials, MOOCs) and in person (summer/winter schools) to learn the practice and theory of different types of methods and applications.

- Develop shared curriculum and competency frameworks to bring together experiences and skill sets. This requires ongoing development and evaluation of pedagogical approaches (i.e. delivery methods and resources) related to SES modeling, and how they relate to modeling competencies. The emerging competency frameworks will enable the development of distinct and recognizable profiles in SES modeling and provide the basis for higher education to create courses and programs.

- Offer training in the methods of engagement with diverse types of stakeholders to allow the formation of actionable science. A closer involvement of stakeholders with the practice of modelers will not only improve skills of modelers, but also these stakeholders will be empowered in their critical and constructive evaluation of the use of computational models. It will be especially important for model users to learn what leads to certain model outcomes, and what we can learn from successes and failures in SES model applications.

\subsection{Consolidating methodological knowledge for SES modeling}

The preponderance of literature in SES modeling is on single case study applications. While these case studies have been useful for identifying lines of enquiry that warrant further research, we envision that continuing with the status quo seems unlikely to yield large benefits around addressing the above delineated challenges. To be able to increase and accelerate SES science, we conclude that one of the prime research opportunities is in pursuing multiple and comparative case studies especially in relation to research design. The design of these studies should focus on the methodological choices for treating the challenges identified in this study and how they affect model outcomes. We see at least two ways in which this research direction can be implemented. Firstly, large projects can trial and assess different methodological choices, and their implications in terms of the model's utility and impact on actionable science. Secondly, multiple projects can be designed or executed in similar ways to allow for meta-analysis and cross-case study comparisons. Of course, to encourage collaboration and research around developing and testing methodologies, there is a need for funding commitment that value efforts around methodological experimentation and synthesis.

Moreover, the SES modeling community needs to adopt reflective, consistent, and systematic reporting practices with explicit focus on considerations within the modeling process itself. Key considerations would be identifying decision forks, explaining the rationale behind choices with linkages to contextual as well as behavioral factors (e.g. biases), critical reflections on "what actually happened" versus "what was planned", illuminating the muddling through moments and failures rather than textbook descriptions, and identifying critical learning incidents. The accumulation of a robust and consistent body of knowledge over time can lead to multiple benefits. Firstly, synthesizing and consolidating this knowledge (e.g. in the form of guidelines and lessons) will provide practical advice for researchers and practitioners on the design and implementation of SES modeling methodologies. Secondly, it will help identify those promising research leads that warrant further methodological developments.

\subsection{Shift towards integrated uncertainty management}

Despite theoretical and methodological advances towards more integrated ways for characterizing and assessing multiple sources of uncertainty in the SES modeling process, many of these developments have not become common practice. The norm for uncertainty assessment is still narrowly limited largely to parametric analysis of models. Moreover, reported treatment of uncertainty is often detached from the science investigated, rather than linked to the knowledge gaps, and model purpose and use in addressing these gaps. 
Advancing integrated uncertainty assessment practices has the potential to improve the way all other delineated grand challenges are addressed and prioritized. Conversely, mis- or under-treatment of uncertainty may exacerbate the other challenges. Addressing uncertainty can thus be an integrative lens to assemble the aforementioned challenges.

Most of the challenges discussed in here are epistemic and surmountable, mainly relating to progressing our model structure representations and overall modeling practices. Nevertheless, there will always be a level of structural, irreducible uncertainty because of the inevitable human inability to understand and represent the real world, and because of the inherent complexity of SES that prevents succinct representation with the knowledge and data at hand. It is the role of uncertainty management to prioritize the sources of uncertainty, identify the value of new information and to characterize and communicate the resultant limitations.

Uncertainty communication is a promising subfield of uncertainty assessment and management, where SES modelers should work closely with researchers in the development of methods informed by interdisciplinary knowledge (e.g. behavioral science, data analytics) of how humans process information, perceive and interpret risk, and make decisions under uncertainty. This should lead to improved understanding of how models can be best developed and applied, as reflected in: improved process design to elevate value for stakeholders, effective balance between the use of qualitative and quantitative methods, and fit-for-purpose visualization and communication methods. The effective use of visualization and communication methods is particularly important for SES modeling, where the dimensions of output data grow quickly (Lee et al., 2015), necessitating novel and appealing ways of distilling and communicating key policy insights.

\section{Acknowledgments}

This work was supported by the SESYNC (Socio-Environmental Synthesis Center) under funding received by the National Science Foundation DBI-1052875. Furthermore, Albert Kettner was supported by the CSDMS project, funded by The US National Science Foundation (grant 0621695). Steven Lade was supported by the Swedish Research Council Formas (grant 2014-589).

\section{References}

Abar, S., Theodoropoulos, G. K., Lemarinier, P., \& O'Hare, G. M. (2017). Agent based modelling and simulation tools: a review of the state-of-art software. Computer Science Review, 24, 13-33. https://doi.org/10.1016/j.cosrev.2017.03.001.

An, L. (2012) Modeling human decisions in coupled human and natural systems: Review of agent-based models. Ecological Modelling, 229, 25-36.

Anderies, J.M., Janssen, M.A., Bousquet, F., Cardenas, J.-C., Castillo, D., Lopez, M.-C., Tobias, R., Vollan, B., \& Wutich, A. (2011). The challenge of understanding decisions in experimental studies of common pool resource governance. Ecological Economics, 70(9), 1571-1579.

Athanasiadis, I. N. (2017). How to Start an Environmental Software Project. In Environmental Software Systems. Computer Science for Environmental Protection: 12th IFIP WG 5.11 International Symposium, ISESS 2017, Zadar, Croatia, May 10-12, 2017, Proceedings 12 (pp. 395-407). Springer International Publishing.

Baker, M. (2016) Is there a reproducibility crisis? Nature, 533, 452-454.

Bankes, S., Lempert, R., \& Popper, S. (2002) Making Computational Social Science Effective: Epistemology, Methodology, and Technology. Social Science Computer Review, 20(4), 377-388. https://doi.org/10.1177\%2F089443902237317.

Barberá, P., \& Rivero, G. (2015). Understanding the political representativeness of Twitter users. Social Science Computer Review, 33(6), 712-729.

Bayat, B., Crasta, N., Crespi, A., Pascoal, A.M., \& ljspeert, A. (2017) Environmental Monitoring Using Autonomous Vehicles: A Survey of Recent Searching Techniques. Current Opinion in Biotechnology, 45, 76-84. https://doi.org/10.1016/j.copbio.2017.01.009.

Beckage, B., Gross, L.J., Lacasse, K., Carr, E., Metcalf, S.S., Winter, J.M., Howe, P.D., Fefferman, N., Franck, T., Zia, A., Kinzig, A., \& Hoffman, F.M. (2018) Linking models of human behaviour and climate alters projected climate change. Nature Climate Change, 8 (1), 79-84. https://doi.org/10.1038/s41558-017-0031-7.

Belete, G. F., Voinov, A., \& Laniak, G. F. (2017a). An overview of the model integration process: From pre-integration assessment to testing. Environmental modelling \& software, 87, 49-63.

Belete, G.F., Voinov, A., \& Morales, J. (2017b) Designing the Distributed Model Integration Framework - DMIF. Environmental Modelling \& Software, 94, 112-126. https://doi.org/10.1016/j.envsoft.2017.04.003. 
Belete, G, F., Voinov, A., Arto, I., Dhavala, K., Bulavskaya, T., Niamir, L., Moghayer, S. \& Filatova, T. (2019) Exploring LowCarbon Futures: A Web Service Approach to Linking Diverse Climate-Energy-Economy Models. Energies 12 (15), 2880. https://doi.org/10.3390/en12152880.

Bell, A., Calvo-Hernandez, C., \& Oppenheimer, M. (2019). Migration, Intensification, and Diversification as Adaptive Strategies. Socio-Environmental Systems Modelling, 1, 16102. https://doi.org/10.18174/sesmo.2019a16102.

Bell, A.R., Robinson, D.T., Malik, A., \& Dewal, S. (2015) Modular ABM development for improved dissemination and training. Environmental Modelling \& Software, 73, 189-200. https://doi.org/10.1016/j.envsoft.2015.07.016.

Bert, F.E., Rovere, S.L., Macal, C.M., North, M.J., \& Podestra, G.P. (2014) Lessons from a comprehensive validation of an agent based-model: The experience of the Pampas Model of Argentinean agricultural systems. Ecological Modelling, 273, 284-298. https://doi.org/10.1016/j.ecolmodel.2013.11.024.

Beven, K. (2016) Facets of uncertainty: epistemic uncertainty, non-stationarity, likelihood, hypothesis testing, and communication. Hydrological Science Journal, 61, 1652-1665. https://doi.org/10.1080/02626667.2015.1031761.

Bitterman, P., \& Bennett, D.A. (2016) Constructing stability landscapes to identify alternative states in coupled socialecological agent-based models. Ecology and Society, 21(3). https://doi.org/10.5751/ES-08677-210321.

Blazquez, D., \& Domenech, J. (2018). Big Data sources and methods for social and economic analyses. Technological Forecasting and Social Change, 130, 99-113.

Bonabeau, E. (2002). Agent-based modeling: Methods and techniques for simulating human systems. Proceedings of the National Academy of Sciences 99 (Supplementary 3), 7280-7287. doi: 10.1073/pnas.082080899.

Bone, C., Johnson, B., Nielsen-Pincus, M., Sproles, E., \& Bolte, J. (2013). A Temporal Variant-Invariant Validation Approach for Agent-based Models of Landscape Dynamics. Transactions in GIS, 18(2), 161-182. https://doi.org/10.1111/tgis.12016.

Bonzanigo, L., Brown, C., Harou, J.J., Hurford, A., Ray, P., \& Karki, P. (2015). South Asia - Investment decision making in hydropower: decision tree case study of the upper Arun hydropower project and Koshi basin hydropower development in Nepal. Washington, D.C.: World Bank Group. http://documents.worldbank.org/curated/en/179901476791918856/South-Asia-Investment-decision-making-inhydropower-decision-tree-case-study-of-the-upper-Arun-hydropower-project-and-Koshi-basin-hydropowerdevelopment-in-Nepal

Brandt, T., Bendler, J., \& Neumann, D. (2017). Social media analytics and value creation in urban smart tourism ecosystems. Information \& Management, 54(6), 703-713. https://doi.org/10.1016/j.im.2017.01.004.

Brooks, H. (1984). The Resolution of Technically Intensive Public Policy Disputes. Science, Technology, \& Human Values, 9(1), 39-50. https://doi.org/10.1177/016224398400900106.

Brown, D.G., Page, S.E., Riolo, R., Zellner, M.L., \& Rand, W. (2005). Path dependence and the validation of agent-based spatial models of land use. International Journal of Geographical Information Science, Special Issue on Land Use Dynamics, 19 (2): 153-174. https://doi.org/10.1080/13658810410001713399.

Brugnach, M., Pahl-Wostl, C., Lindenschmidt, K.E., Janssen, J.A.E.B., Filatova, T., Mouton, A., Holtz, G., van der Keur, P., \& Gaber, N. N. (2008). Complexity and uncertainty: rethinking the modelling activity. In: Jakeman A. J., Voinov A. A., Rizzoli A. E., Chen S. H. (eds.), Environmental modelling, software and decision support: state of the art and new perspectives, Chapter 4, Amsterdam, Elsevier, pp.49-68.

Bungartz, H.J., and Griebel, M. (2004). Sparse grids. Acta Numerica, 13, 147-269. https://doi.org/10.1017/S0962492904000182.

Busch, J., Godoy, F., Turner, W.R., \& Harvey, C.A. (2011). Biodiversity co-benefits of reducing emissions from deforestation under alternative reference levels and levels of finance. Conservation Letters, 4(2), pp. 101-115.

Castilla-Rho J.C., Rojas, R., Andersen, M.S, Holley, C., \& Mariethoz, G. (2017). Social tipping points in global groundwater management. Nature Human Behaviour, 1, 640-649. https://doi.org/10.1038/s41562-017-0181-7.

Certomà, C., Corsini, F., \& Rizzi, F. (2015). Crowdsourcing Urban Sustainability. Data, People and Technologies in Participatory Governance. Futures, 74, 93-106. https://doi.org/10.1016/j.futures.2014.11.006.

Chakladar, S. (2016). A model driven engineering framework for simulation experiment management. PhD dissertation, Auburn University.

Chang, Y.C., Hong, F.W., \& Lee, M.T. (2008). A system dynamic based DSS for sustainable coral reef management in Kenting coastal zone, Taiwan. Ecological Modelling, 211(1-2), 153-168.

Charli-Joseph, L., Siqueiros-Garcia, J.M., Eakin, H., Manuel-Navarrete, D., \& Shelton, R. (2018). Promoting agency for socialecological transformation: A transformation-lab in the Xochimilco social-ecological system. Ecology and Society, 23(2), 46.

Cheong, S.-M., Brown, D. G., Kok, K., and Lopez-Carr, D. (2011). Mixed methods in land change research: towards integration. Transactions of the Institute of British Geographers, 37(1), 8-12. https://doi.org/10.1111/j.1475-5661.2011.00482.x.

Chen, X., Elmes, G., Ye, X., \& Chang, J. (2016). Implementing a real-time Twitter-based system for resource dispatch in disaster management. GeoJournal, 81(6) 863-873. https://doi.org/10.1007/s10708-016-9745-8.

Chin, A., Coelho, R., Nugent, R., Munakata, R., \& Puig-Suari, J. (2008, September). CubeSat: the pico-satellite standard for research and education. In: AIAA Space 2008 Conference $\&$ Exposition (p. 7734).

Contreras, D., Guiot, J., Suarez, R., Kirman, A. (2018) Reaching the human scale: A spatial and temporal downscaling approach to the archaeological implications of paleoclimate data. Journal of Archaeological Science, 93, 54-67. 
Coron, L. Andreassian, V., Perrin, C., Lerat, J., Vaze, J., Bourqui, M., \& Hendrickx, F. (2012). Crash testing hydrological models in contrasted climate conditions: an experiment on 216 Australian catchments. Water Resources Research, 48(5), W05552. https://doi.org/10.1029/2011WR011721.

Coleman, J. (1998). Foundations of Social Theory. Harvard University Press.

Crow, M.M., \& Dabars, W.B. (2015). Designing the New American University, John Hopkins University Press, Baltimore.

De Haan, Fjalar J., and Jan Rotmans. (2018). "A Proposed Theoretical Framework for Actors in Transformative Change." Technological Forecasting and Social Change 128, 275-86. https://doi.org/10.1016/j.techfore.2017.12.017.

Dellink, R., Chateau, J., Lanzi, E., \& Magné, B. (2017) Long-term economic growth projections in the Shared Socioeconomic Pathways. Global Environmental Change, 42, pp. 200-214.

Deletic, A., Dotto, C.B.S., McCarthy, D.T., Kleidorfer, M., Freni, G., Mannina, G., Uhl, M., Henrichs, M., Fletcher, T.D., Rauch, W., Bertrand-Krajewski, J.L., \& Tait, S. (2012). Assessing uncertainties in urban drainage models. Physics and Chemistry of the Earth, 42-44: 3-10.

Di Baldassarre, G., Viglione, A., Carr, G., Kuil, L., Yan, K., Brandimarte, L., \& Blöschl, G. (2015). Debates-Perspectives on socio-hydrology: Capturing feedbacks between physical and social processes. Water Resources Research, 51(6), 4770-4781. https://doi.org/10/f3n3p5.

Di Baldassarre, G., Brandimarte, L., \& Beven, K. (2016). The seventh facet of uncertainty: wrong assumptions, unknowns and surprises in the dynamics of human-water systems. Hydrological Sciences Journal, 61(9), 1748-1758. https://doi.org/10.1080/02626667.2015.1091460.

Drosatos, G., Efraimidis, P. S., Athanasiadis, I.N., D'Hondt, E., \& Stevens, M. (2012). A privacy-preserving cloud computing system for creating participatory noise maps. In Computer Software and Applications Conference (COMPSAC), 2012 IEEE 36th Annual (pp. 581-586). IEEE. https://doi.org/10.1109/COMPSAC.2012.78.

Drosatos, G., Efraimidis, P. S., Athanasiadis, I. N., Stevens, M., \& D’Hondt, E. (2014). Privacy-preserving computation of participatory noise maps in the cloud. Journal of Systems and Software, 92, 170-183. https://doi.org/10.1016/j.jss.2014.01.035.

Elbattah, M. (2018). Hybrid systems modelling aided by machine learning with applications in healthcare, Doctoral dissertation, NUI Galway.

Elsawah, S., Guillaume J.H.A., Filatova T., Rook J., \& Jakeman, A.J. (2015). A methodology for eliciting, representing, and analysing stakeholder knowledge for decision making on complex socio-ecological systems: From cognitive maps to agent-based models. Journal of Environmental Management, 151, 500-516. https://doi.org/10.1016/j.jenvman.2014.11.028.

Epstein, J.M., \& Axtell, R. (1996). Growing Artificial Societies: Social Science from the Bottom Up. Cambridge, MA: MIT Press.

Evans, T., Robinson, D.T., \& Schmitt-Harsh, M. (2013). Limitations, challenges, and solutions to integrating carbon dynamics with land-use models. Brown, D.G., Robinson, D.T., French, N.H.F., and B.C. Reed (eds), in Land use and the carbon cycle: Advances in Integrated Science, Management, and Policy. Cambridge University Press. Pp. 178-208.

Fang, S., Xu, L.D., Zhu, Y., Ahati, J., Pei, H., Yan, J., \& Liu, Z. (2014). An Integrated System for Regional Environmental Monitoring and Management Based on Internet of Things. IEEE Transactions on Industrial Informatics, 10 (2), 15961605. https://doi.org/10.1109/TII.2014.2302638.

Farmer, J.D., \& Foley, D. (2009). The economy needs agent-based modelling. Nature, 460, 685-686. https://doi.org/10.1038/460685a.

Farmer, J.D., Hepburn, C., Mealy, P., and Teytelboym, A. (2015). A Third Wave in the Economics of Climate Change. Environmental and Resource Economics, 62(2): 329-357. https://doi.org/10.1007/s10640-015-9965-2.

Farrell, H. (2017). How Facebook Stymies Social Science. The Chronicle of Higher Education, December 19. https://www.chronicle.com/article/How-Facebook-Stymies-Social/242090.

Ferson, S., \& Sentz, K. (2016). Epistemic Uncertainty in Agent-based Modeling. In S. Freitag, R. L. Muhanna, \& R. L. Mullen (Eds.), Proceedings of the 7th International Workshop of Reliable Engineering Computing: Computing with Polymorphic Uncertain Data (pp. 65-82). Bochum, Germany. Retrieved from http://rec2016.rub.de/downloads/rec2016_proceedings.pdf.

Filatova T., Verburg, P.H., Parker, D.C., \& Stannard, C.A. (2013). Spatial agent-based models for socio-ecological systems: challenges and prospects. Environmental Modelling \& Software, 45, 1-7.

Filatova T, Polhill, J.G., \& van Ewijk, S. (2016). Regime shifts in coupled socio-environmental systems: Review of modelling challenges and approaches. Environmental Modelling \& Software, 75:333-347. https://doi.org/10.1016/j.envsoft.2015.04.003.

Fischhoff, B. (2006). Behaviorally Realistic Risk Management. In R. J. Daniels, D. F. Kettl, \& H. Kunreuther (Eds.), On Risk and Disaster: Lessons from Hurricane Katrina (pp. 77-88). Philadelphia: University of Pennsylvania Press.

Fischhoff, B., Slovic, P., \& Lichtenstein, S. (1982). Lay foibles and expert fables in judgments about risk. The American Statistician, 36(3), 240-255. https://doi.org/10/fq48fh.

Forni, M, \& Lippi, M. (1997). Aggregation and the Microfoundations of Dynamic Macroeconomics. Oxford: Oxford University Press.

Fowler, H.J., Blenkinsop, S., \& Tebaldi, C. (2007). Linking climate change modelling to impacts studies: recent advances in downscaling techniques for hydrological modelling. International Journal of Climatology, 27(12), 1547-1578. https://doi.org/10.1002/joc.1556. 
Fu, B., Guillaume, J.H.A., \& Jakeman, A.J. (2015). An iterative method for discovering feasible management interventions and targets conjointly using uncertainty visualizations. Environmental Modelling \& Software, 71, 159-173. https://doi.org/10.1016/j.envsoft.2015.05.017.

Gibert, K., Horsburgh, J.S., Athanasiadis, I.N., \& Holmes, G. (2018). Environmental Data Science, Environmental Modelling \& Software, 106, 4-12.

Gilligan, J.M. (2018). Accounting for the human factor. Nature Climate Change, 8, 14-15. https://doi.org/10.1038/s41558017-0038-0.

Gibson, C.C., Ostrom, E., \& Ahn, T.K. (2000). The concept of scale and the human dimensions of global change: a survey. Ecological Economics, 32(2), 217-239. https://doi.org/10.1016/S0921-8009(99)00092-0.

Goring, S.J., Weathers, K.C., Dodds, W.K., Soranno, P.A., Sweet, L.C., Cheruvelil, K.S., Kominoski, J.S., Rüegg, J., Thorn, A.M., \& Utz, R.M. (2014). Improving the culture of interdisciplinary collaboration in ecology by expanding measures of success. Frontiers in Ecology and the Environment, 12(1), 39-47. https://doi.org/10.1890/120370.

Grainger, S., Mao, F., \& Buytaert, W. (2016). Environmental data visualisation for non-scientific contexts: Literature review and design framework. Environmental Modelling \& Software, 85, 299-318. https://doi.org/10.1016/j.envsoft.2016.09.004

Gray S.A., Zanre E., \& Gray S.R.J. (2014). Fuzzy Cognitive Maps as Representations of Mental Models and Group Beliefs. In: Papageorgiou E. (eds) Fuzzy Cognitive Maps for Applied Sciences and Engineering. Intelligent Systems Reference Library, vol 54. Springer, Berlin, Heidelberg. https://doi.org/10.1007/978-3-642-39739-4_2.

Gray, S., Voinov., A., Paolisso, M., Jordan, R., BenDor, T., Bommel, P., Glynn, P., Hedelin, B., Hubacek, K., Introne, J., Kolagani, N., Laursen, B., Prell, C., Schmitt-Olabisi, L., Singer, A., Sterling, E., \& Zellner, M. (2018). Purpose, Processes, Partnerships, and Products: 4Ps to advance Participatory Socio-Environmental Modeling. Ecological Applications, 28(1), 46-61.

Groves, D.G., and Lempert, R.J. (2007). A new analytic method for finding policy-relevant scenarios. Global Environmental Change, 17(1), 73-85. https://doi.org/10.1016/j.gloenvcha.2006.11.006.

Guillaume, J.H.A., Hunt, R.J., Comunian, A., Blakers, R.S., \& Fu, B. (2016). Methods for Exploring Uncertainty in Groundwater Management Predictions. In: Jakeman A.J., Barreteau O., Hunt R.J., Rinaudo JD., Ross A. (eds) Integrated Groundwater Management. Springer, Cham. https://doi.org/10.1007/978-3-319-23576-9_28.

Guivarch, C., Lempert, R., \& Trutnevyte, E. (2017). Scenario techniques for energy and environmental research: An overview of recent developments to broaden the capacity to deal with complexity and uncertainty. Environmental Modelling \& Software, 97, 201-210. https://doi.org/10.1016/j.envsoft.2017.07.017.

Haasnoot, M., Van Deursen, W. P. A., Guillaume, J. H., Kwakkel, J. H., van Beek, E., \& Middelkoop, H. (2014). Fit for purpose? Building and evaluating a fast, integrated model for exploring water policy pathways. Environmental Modelling \& Software, 60, 99-120. https://doi.org/10.1016/j.envsoft.2014.05.020.

Hamilton, S.H., Elsawah, S., Guillaume, J.H., Jakeman, A.J., \& Pierce, S.A. (2015). Integrated assessment and modelling: overview and synthesis of salient dimensions. Environmental Modelling \& Software, 64, 215-229. https://doi.org/10.1016/j.envsoft.2014.12.005.

Happe, K. (2005). Agent-based modelling and sensitivity analysis by experimental design and metamodelling: an application to modelling regional structural change. In: XIth International Congress of the European Association of Agricultural Economists. European Association of Agricultrual Economists, The Future of Rural Europe in the Global Agri-Food System, Copenhagen, Denmark, August 24-27, 2005.

Harp, D.R., \& Vesselinov, V.V. (2012). An agent-based approach to global uncertainty and sensitivity analysis. Computers \& Geosciences, 40, 19-27. https://doi.org/10.1016/j.cageo.2011.06.025.

Heppenstall, A.J.J., Crooks, A.T., See, L.M., \& Batty, M. (2012). Agent-Based Models of Geographical Systems. Springer: Berlin. pp 1-759

Hoch, C.J., Zellner, M.L., Milz, D.C., Radinsky, J., \& Lyons, L. (2015). Seeing is not believing: cognitive bias and modelling in collaborative planning. Planning Theory and Practice, 16 (3), 319-335. https://doi.org/10.1080/14649357.2015.1045015.

Howe, P.D., \& Leiserowitz, A. (2013). Who Remembers a Hot Summer or a Cold Winter? The Asymmetric Effect of Beliefs about Global Warming on Perceptions of Local Climate Conditions in the U.S., Global Environmental Change, 23 (6), 1488-1500. https://doi.org/10/f5phcx.

Ioannidis, J.P.A. (2013). Informed Consent, Big Data, and the Oxymoron of Research That Is Not Research. The American Journal of Bioethics, 13 (4), 40-42. https://doi.org/10.1080/15265161.2013.768864.

Jakeman, A.J., Barreteau, O., Hunt, R., Rinaudo, J.D., \& Ross, A. (2016). Integrated Groundwater Management. Springer.

Jakeman A.J., Jakeman J.D. (2016). An Overview of Methods to Identify and Manage Uncertainty for Modelling Problems in the Water-Environment-Agriculture Cross-Sector. In: Anderssen R., Broadbridge P., Fukumoto Y., Kajiwara K., Simpson M., Turner I. (eds) Agriculture as a Metaphor for Creativity in All Human Endeavors. FMfI 2016. Mathematics for Industry, vol 28. Springer, Singapore, DOI https://doi.org/10.1007/978-981-10-7811-8_15.

Jakeman, A.J., Letcher, R.A., \& Norton, J.P. (2006). Ten iterative steps in development and evaluation of environmental models. Environmental Modelling \& Software, 21, 602-614. https://doi.org/10.1016/j.envsoft.2006.01.004.

Janssen, M.A. (2016). Impact of diverse behavioral theories on environmental management: Explorations with Daisyworld. In: 2016 Winter Simulation Conference (WSC) (pp. 1690-1701). https://doi.org/10.1109/WSC.2016.7822217.

Janssen, M.A. (2017). The Practice of Archiving Model Code of Agent-Based Models. Journal of Artificial Societies and Social Simulation, 20(1), 2. https://doi.org/10.18564/jasss.3317. 
Janssen, P.H.M., Petersen, A.C., van der Sluijs, J.P., Risbey, J.S., \& Ravetz, J.R. (2003). RIVM/MNP Guidance for Uncertainty Assessment and Communication: Quickscan Hints \& Actions List. 90-6960-105-2, RIVM/MNP. Available from http://www.nusap.net.

Jasanoff, S. (2003). Technologies of humility: citizen participation in governing science. Minerva, 41(3), 223-244.

Jefferson, J.L., Gilbert, J.M., Constantine, P.G., \& Maxwell, R.M. (2015). Active subspaces for sensitivity analysis and dimension reduction of an integrated hydrologic model. Computers \& Geosciences, 83, 127-138. https://doi.org/10.1016/j.cageo.2015.07.001.

Jiang, Q., Bregt, A.K., \& Kooistra, L. (2018). Formal and Informal Environmental Sensing Data and Integration Potential: Perceptions of Citizens and Experts. Science of The Total Environment, 619-620, $1133-42$. https://doi.org/10.1016/j.scitotenv.2017.10.329.

Jick, T. D. (1979). Mixing Qualitative and Quantitative Methods: Triangulation in Action. Administrative Science Quarterly, 24(4), 602-611. https://doi.org/10/dd4b5d.

Jongman, B., Winsemius, H. C., Aerts, J. C., de Perez, E. C., van Aalst, M. K., Kron, W., \& Ward, P. J. (2015). Declining vulnerability to river floods and the global benefits of adaptation. Proceedings of the National Academy of Sciences, 112(18), E2271-E2280.

Jordan, R., Gray, S., Zellner, M., Glynn, P., Voinov, A., Hedelin, B., Sterling, E., Leong, K., Schmitt Olabisi, L., Hubacek, K., Bommel, P., BenDor, T., Jetter, A., Laursen, B., Singer, A., Giabbanelli, P., Kolagani, N., Basco Carrera, L., \& Jenni, K. (2018). 12 Questions for the participatory modeling community. Earth's Future, 6(8), 1046-1057.

Kaipio, J., and Somersalo, E. (2006). Statistical and computational inverse problems, Vol. 160. Springer Science \& Business Media.

Kalra, N., Hallegatte, S., Lempert, R., Brown, C., Fozzard, A., Gill, S., \& Shah, A. (2015). Agreeing on robust decisions: new processes for decision making under deep uncertainty. Policy Research working paper; no. WPS 6906. Washington, DC: World Bank Group. http://documents.worldbank.org/curated/en/365031468338971343/Agreeing-on-robustdecisions-new-processes-for-decision-making-under-deep-uncertainty.

Kasprzyk, J.R., Nataraj, S., Reed, P.M., \& Lempert, R.J. (2013). Many objective robust decision making for complex environmental systems undergoing change. Environmental Modelling \& Software, 42, 55-71. https://doi.org/10/f4scqr.

Kelly, R.A., Jakeman, A.J., Barreteau, O., Borsuk, M.E., Elsawah, S., Hamilton, S.H., Henriksen, H.J., Kuikka, S., Maier, H.R., Rizzoli, A.E., van Delden, H., \& Voinov, A., 2013. Selecting among five common modelling approaches for integrated environmental assessment and management. Environmental Modelling \& Software, 47, 159-181. https://doi.org/10.1016/j.envsoft.2013.05.005.

Kettner, A.J., \& Syvitski, J.P.M. (2016). Uncertainty and Sensitivity in Surface Dynamics Modeling. Computers \& Geosciences, 90, 1-5. https://doi.org/10.1016/j.cageo.2016.03.003.

Kirman, A.P. (1992). Whom or what does the representative individual represent? Journal of Economic Perspectives, 6(2), 117-136. https://doi.org/10.1257/jep.6.2.117.

Kitchin, R. (2013). Big Data and Human Geography: Opportunities, Challenges and Risks. Dialogues in Human Geography, 3 (3): 262-67. https://doi.org/10.1177/2043820613513388.

Kline, J.D., White, E.M., Fischer, A.P., Steen-Adams, M.M., Charnley, S., Olsen, C.S., Spies, T.A., \& Bailey, J.D. (2017). Integrating social science into empirical models of coupled human and natural systems. Ecology and Society, 22(3). http://www.jstor.org/stable/26270162.

Kretschmer, B. \& Peterson, S. (2010). Integrating bioenergy into computable general equilibrium models - A survey. Energy Economics, 32(3), pp. 673-686.

Kryvasheyeu, Y., Chen, H., Obradovich, N., Moro, E., Van Hentenryck, P., Fowler, J., \& Cebrian, M. (2016). Rapid Assessment of Disaster Damage Using Social Media Activity. Science Advances, 2 (3), e1500779. https://doi.org/10/gc5tfp.

Kwakkel, J.H., \& Pruyt, E. (2013). Exploratory Modeling and Analysis, an approach for model-based foresight under deep uncertainty. Technological Forecasting and Social Change, 80(3), 419-431. https://doi.org/10.1016/j.techfore.2012.10.005.

Lade, S.J., Haider, L.J., Engström, G., \& Schlüter, M. (2017). Resilience offers escape from trapped thinking on poverty alleviation. Science Advances, 3(5), e1603043. https://doi.org/10.1126/sciadv.1603043.

Lade, S.J. \& Niiranen, S. (2017). Generalized modeling of empirical social-ecological systems. Natural Resource Modeling, 30(3), e12129. https://doi.org/10.1111/nrm.12129.

Lahsen, M., \& Nobre, C.A. (2007). Challenges of connecting international science and local level sustainability efforts: the case of the Large-Scale Biosphere-Atmosphere Experiment in Amazonia. Environmental Science \& Policy, 10(1), 6274. https://doi.org/10.1016/j.envsci.2006.10.005.

Lahtinen, T.J., Guillaume, J.H., \& Hämäläinen, R.P. (2017). Why pay attention to paths in the practice of environmental modelling? Environmental Modelling \& Software, 92, 74-81. https://doi.org/10.1016/j.envsoft.2017.02.019.

Lamberson P.J., \& Page, S.E. (2012). Tipping Points. Santa Fe Institute Working Papers.

Lane, D.C. \& Kopainsky, B. (2017). Editorial - Natural Resource Management: Contributions of System Dynamics to Research, Policy and Implementation. Systems Research and Behavioral Science, 34, 378-385.

Lattuca, L.R. (2001). Creating Interdisciplinarity: Interdisciplinary Research and Teaching Among College and University Faculty (1st ed). Nashville: Vanderbilt University Press.

Lawrence Livermore National Laboratory. (2012). CF Conventions and Metadata. http://cfconventions.org/. 
Lee J.-S., Filatova, T., Ligmann-Zielinska, A., Hassani-Mahmooei, B., Stonedahl, F., Lorscheid, I., Voinov, A., Polhill, J.G., Sun, Z., \& Parker, D.C. (2015). The Complexities of Agent-Based Modeling Output Analysis. Journal of Artificial Societies and Social Simulation, 18(4). https://doi.org/10.18564/jasss.2897.

Lee, D.B. Jr. (1973). Requiem for large-scale models. Journal of the American Institute of Planners, 39, pp. $163-178$. https://doi.org/10.1080/01944367308977851.

Lempert, R.J. (2002). A new decision sciences for complex systems. Proceedings of the National Academy of Sciences, 99 (suppl 3) 7309-7313. https://doi.org/10.1073/pnas.082081699.

Lempert, R.J., Groves, D.G., Popper, S.W., \& Bankes, S.C. (2006). A General, Analytic Method for Generating Robust Strategies and Narrative Scenarios. Management science, 52(4): 514-528. https://doi.org/10.1287/mnsc.1050.0472.

Levin, S.A. (1992). The Problem of Pattern and Scale in Ecology: The Robert H. MacArthur Award Lecture. Ecology, 73, 19431967. https://doi.org/10.2307/1941447.

Levin, S., Xepapadeas, T., Crepin, A.-S., Norber, J., de Zeeuw, A., Folke, C., Hughes, T., Arrow, K., Barrett, S., Daily, G., Ehrlich, P., Kautsky, N., Maler, K.-G., Polasky, S., Troell, M., Vincent, J.R., \& Walker, B. (2013). Social-ecological systems as complex adaptive systems: modeling and policy implications. Environment and Development Economics, 18(2), 111132. https://doi.org/10.1017/S1355770X12000460.

Ligmann-Zielinska, A., Kramer, D.B., Cheruvelil, K.S., \& Soranno, P.A. (2014). Using Uncertainty and Sensitivity Analyses in Socioecological Agent-Based Models to Improve Their Analytical Performance and Policy Relevance. PLOS ONE, 9(10), e109779. https://doi.org/10.1371/journal.pone.0109779.

Lippe, M., Bithell, M., Gotts, N., Natalini, D., Barbrook-Johnson, P., Giupponi, C., Hallier, M. Hofstede, G.J., Le Page, C., Matthews, R.B., Schlüter, M., Smith, P., Teglio, A., Thellmann, K. (2019). Using agent-based modelling to simulate social-ecological systems across scales. Geolnformatica, 23(2), 269-298.

Lokers, R., Knapen, R., Janssen, S., van Randen, Y., \& Jansen, J. (2016). Analysis of Big Data technologies for use in agroenvironmental science. Environmental Modelling \& Software, 84, 494-504. https://doi.org/10.1016/j.envsoft.2016.07.017.

Luvuno, L., Biggs, R., Stevens, N., \& Esler, K. (2018). Woody encroachment as a social-ecological regime shift. Sustainability 10(7): 2221. https://doi.org/10.3390/su10072221.

Lum, K. (2017). Limitations of Mitigating Judicial Bias with Machine Learning. Nature Human Behaviour, 1 (7): 0141. https://doi.org/10.1038/s41562-017-0141.

Lum, K., \& Isaac, W., 2016. To Predict and Serve? Significance 13 (5), 14-19. https://doi.org/10.1111/j.17409713.2016.00960.x.

MacMynowski, D.P. (2007). Pausing at the brink of interdisciplinarity: power and knowledge at the meeting of social and biophysical science. Ecology and Society, 12(1): 20. http://www.ecologyandsociety.org/vol12/iss1/art20.

Mai, J.-E. (2016). Big Data Privacy: The Datafication of Personal Information. The Information Society, 32 (3): $192-99$. https://doi.org/10.1080/01972243.2016.1153010.

Maier, H.R., Guillaume, J.H.A., van Delden, H., Riddell, G.A., Haasnoot, M., \& Kwakkel, J.H. (2016). An uncertain future, deep uncertainty, scenarios, robustness and adaptation: How do they fit together? Environmental Modelling \& Software, 81, 154-164. https://doi.org/10.1016/j.envsoft.2016.03.014.

Maliapen, M. (2009). Clinical Genomics Data Use: Protecting Patients Privacy Rights. Studies in Ethics, Law, and Technology, 3 (1). https://doi.org/10.2202/1941-6008.1080.

Mallavarapu, A., Lyons, L., Shelley, T., Zellner, M., Minor, E., \& Slattery, B. (2015). Developing Computational Methods to Measure and Track Learners' Spatial Reasoning in an Open-Ended Simulation. Journal of Educational Data Mining, 7(2), 49-82. https://jedm.educationaldatamining.org/index.php/JEDM/article/view/JEDM122.

Manson, S.M., \& Evans, T. (2007). Agent-based modeling of deforestation in southern Yucatán, Mexico, and reforestation in the Midwest United States. Proceedings of the National Academy of Sciences, 104(52), 20678-20683. https://doi.org/10.1073/pnas.0705802104.

Mattmann, C.A. (2013). Computing: A vision for data science. Nature, 493(7433), $473-475$. https://doi.org/10.1038/493473a.

Matthews, R.B., Gilbert, N.G., Roach, A., Polhill, J.G., \& Gotts, N.M. (2007). Agent-based land-use models: A review of applications. Landscape Ecology, 22(10), pp. 1447-1459.

McPhail, C., Maier, H.R., Kwakkel, J.H., Giuliani, M., Castelletti, A., \& Westra, S. (2018). Robustness Metrics: How Are They Calculated, When Should They Be Used and Why Do They Give Different Results? Earth's Future, 6, 169-191. https://doi.org/10.1002/2017EF000649.

Melgar, L.E.A., Lalith, M., Hori, M., Ichimura, T., \& Tanaka, S. (2014). A Scalable Workbench for Large Urban Area Simulations, Comprised of Resources for Behavioural Models, Interactions and Dynamic Environments. In PRIMA 2014: Principles and Practice of Multi-Agent Systems, 166-81. Lecture Notes in Computer Science. Springer, Cham. https://doi.org/10.1007/978-3-319-13191-7 14.

Merz, B., Vorogushyn, S., Lall, U., Viglione, A., \& Blöschl, G. (2015). Charting unknown waters-On the role of surprise in flood risk assessment and management. Water Resources Research, 51(8), 6399-6416. https://doi.org/10.1002/2015WR017464.

Meyer, R.J., Daniels, R.J., Kettl, D.F., \& Kunreuther, H. (2006). Why we Under-Prepare for Hazards. In On Risk and Disaster: Lessons from Hurricane Katrina (pp. 156-57). Philadelphia: University of Pennsylvania Press. 
Midgley, G., Cavana, R.Y., Brocklesby, J., Foote, J.L., Wood, D.R.R., \& Ahuriri-Driscoll, A. (2013). Towards a new framework for evaluating systemic problem structuring methods. European Journal of Operational Research, 229(1), 143-154. https://doi.org/10/f2z29n.

Miller, T.R.,Baird, T.D., Littlefield, C.M., Kofinas, G., Chapin III, F., \& Redman, C.L. (2008). Epistemological pluralism: reorganizing interdisciplinary research. Ecology and Society, 13(2), 46. http://www.ecologyandsociety.org/vol13/iss2/art46.

Millington, J.D.A., \& Wainwright, J. (2017). Mixed qualitative-simulation methods: Understanding geography through thick and thin. Progress in Human Geography, 41(1), 68-88. https://doi.org/10/f9r4k3.

Milz, D. (2015). Mismatched Scales, Mismatched Intentions: Regional Wastewater Planning on Cape Cod, Massachusetts, USA. PhD, University of Illinois at Chicago.

Milz, D., Zellner, M., Hoch, C., Radinsky, J., Pudlock, K., \& Lyons, L. (2017). Reconsidering Scale: Using Geographic Information Systems to Support Spatial Planning Conversations. Planning Practice \& Research, https://doi.org/10.1080/02697459.2017.1378979.

Mingers, J. (2001). Combining IS Research Methods: Towards a Pluralist Methodology. Information Systems Research, 12(3), 240-259. https://doi.org/10/dx628v.

Mingers, J. (2006). Philosphical foundations: critical realism. In: Mingers, J. Realising system thinking: knowledge and action in management science. Springer. pp. 11-31.

Moore, M.-L., Tjornbo, O., Enfors, E., Knapp, C., Hodbod, J., Baggio, J.A., Norström, A., Olsson, P., \& Biggs, D. (2014). Studying the complexity of change: toward an analytical framework for understanding deliberate social-ecological transformations. Ecology and Society, 19(4), 54. http://dx.doi.org/10.5751/ES-06966-190454.

Morgan, M. G., Fischoff, B., Bostrom, A., \& Atman, C. (2002). Risk communication: A mental models approach, Cambridge University Press, New York.

Muller C.L., Chapman L., Johnston S., Kidd C., Illingworth S., Foody G., Overeem A., \& Leigh R.R. (2015). Crowdsourcing for Climate and Atmospheric Sciences: Current Status and Future Potential. International Journal of Climatology, 35 (11), 3185-3203. https://doi.org/10.1002/joc.4210.

Müller-Hansen, F., Schlüter, M., Mäs, M., Donges, J. F., Kolb, J. J., Thonicke, K., and Heitzig, J., 2017. Towards representing human behavior and decision making in Earth system models - an overview of techniques and approaches. Earth System Dynamics, 8, 977-1007. https://doi.org/10.5194/esd-8-977-2017.

National Research Council. (2006). Facing Hazards and Disasters: Understanding Human Dimensions. National Academies Press. Retrieved from http://www.nap.edu/catalog/11671/facing-hazards-and-disasters-understanding-humandimensions.

National Research Council. (2007). Completing the Forecast: Characterizing and Communicating Uncertainty for Better Decisions Using Weather and Climate Forecasts. Washington, DC: National Academies Press. https://doi.org/10.17226/11699.

Nordhaus, W. (2018). Evolution of modeling of the economics of global warming: changes in the DICE model, 1992-2017. Climatic Change, 148(4), 623-640.

O'Neil, C. (2016). Weapons of Math Destruction: How Big Data Increases Inequality and Threatens Democracy. Reprint edition. Broadway Books.

O'Neill, B.C., Kriegler, E., Ebi, K.L., Kemp-Benedict, E., Riahi, K., Rothman, D.S., van Ruijven, B.J., van Vuuren, D.P., Birkmann, J., Kok, K., Levy, M., \& Solecki, W. (2017). The roads ahead: Narratives for shared socioeconomic pathways describing world futures in the 21st century. Global Environmental Change, 42, 169-180

Paget, N., Bonté, B., Barreteau, O., Pigozzi, G., \& Maurel, P. (2019). An in-silico analysis of information sharing systems for adaptable resources management: a case study of oyster farmers. Socio-Environmental Systems Modelling, 1, 16166. https://doi.org/10.18174/sesmo.2019a16166.

Pahl-Wostl, C., Arthington, A., Bogardi, J., Bunn, S.E., Hoff, H., Lebel, L., Nikitina, E., Palmer, M., Poff, L.N., Richards, K., Schluter, M., Schulze, R., St-Hilaire, A., Tharme, R., Tockner, K., \& Tsegai, D. (2013). Environmental flows and water governance: managing sustainable water uses. Environmental Sustainability, 5, 341-351. https://doi.org/10.1016/j.cosust.2013.06.009.

Parker, A.M., Srinivasan, S.V., Lempert, R.J., \& Berry, S.H. (2015). Evaluating simulation-derived scenarios for effective decision support. Technological Forecasting and Social Change, 91, 64-77. https://doi.org/10/gc3f69.

Peckham, S.D. (2014). The CSDMS Standard Names: Cross-Domain Naming Conventions for Describing Process Models, Data Sets and Their Associated Variables. Proceedings of the Seventh International Congress on Environmental Modeling and Software.

Pesenson, M.Z., Pesenson, I.Z., \& McCollum, B. (2010) The Data Big Bang and the Expanding Digital Universe: HighDimensional, Complex and Massive Data Sets in an Inflationary Epoch. Advances in Astronomy, vol. 2010, Article ID 350891. https://doi.org/10.1155/2010/350891.

Peterson, G.D., Carpenter, S.R., \& Brock, W.A. (2003). Uncertainty and the management of multistate ecosystems: An apparently rational route to collapse. Ecology, 84(6), 1403-1411.

Pindyck, R.S. (2013). Climate Change Policy: What Do the Models Tell Us? Journal of Economic Literature, 51, 860-872. https://doi.org/10.1257/jel.51.3.860.

Platt, J.R. (1964). Strong Inference. Science, 146(3642), 347-353. https://doi.org/10.1126/science.146.3642.347.

Plummer, M.L. (2009) Assessing benefit transfer for the valuation of ecosystem services. Frontiers in Ecology and the Environment, 7(1), 38-45. 
Poggio, L., Simonetti, E., \& Gimona, A. (2018) Enhancing the WorldClim data set for national and regional applications. Science of the Total Environment, 625, 1628-1643.

Polhill, J.G., Sutherland, L.-A., \& Gotts, N.M. (2009). Using Qualitative Evidence to Enhance an Agent-Based Modelling System for Studying Land Use Change. Journal of Artificial Societies and Social Simulation, 13(2), 10.

Pollino, C.A., White, A.K. \& Hart, B.T. (2007). Examination of conflicts and improved strategies for the management of an endangered Eucalypt species using Bayesian networks. Ecological Modelling, 201, 37-59.

Poteete, A.R., Janssen, M.A., \& Ostrom, E. (2010). Working Together: Collective Action, the Commons, and Multiple Methods in Practice. Princeton, N.J: Princeton University Press.

Quinn, J. D., Reed, P. M., Giuliani, M., \& Castelletti, A. (2017). Rival framings: A framework for discovering how problem formulation uncertainties shape risk management trade-offs in water resources systems. Water Resources Research, 53(8), 7208-7233.

Radinsky, J., Milz, D., Zellner, M., Pudlock, K., Witek, C., Hoch, C., \& Lyons, L. (2017). How planners and stakeholders learn with visualization tools: using learning sciences methods to examine planning processes, Journal of Environmental Planning and Management, 60(7), 1296-1323, https://doi.org/10.1080/09640568.2016.1221795.

Railsback, S.F. \& Grimm, V. (2011). Agent-based and Individual-based modeling: a practical introduction. Princeton: Princeton University Press, 352pp.

Rasmussen, C.E., \& Williams, C.K.I (2006). Gaussian Processes for Machine Learning, the MIT Press, ISBN 026218253X. http://www.gaussianprocess.org/gpml.

Refsgaard, J.C., van der Sluijs, J.P., Hojberg, A.L., \& Vanrolleghem, P.A. (2007). Uncertainty in the environmental modelling process - a framework and guidance. Environmental Modelling \& Software, 22, 1543-1556. https://doi.org/10.1016/j.envsoft.2007.02.004.

Renard, B., Kavetski, D., Kuczera, G., Thyer, M., \& Franks, S.W. (2010). Understanding predictive uncertainty in hydrologic modeling: The challenge of identifying input and structural errors. Water Resources Research, 46, W05521. https://doi.org/10.1029/2009WR008328.

Robinson, D. T., Brown, D. G., Parker, D. C., Schreinemachers, P., Janssen, M. A., Huigen, M., Wittmer, H., Gotts, N., Promburom, P., Irwin, E., Berger, T., Gatzweiler, F., \& Barnaud, C. (2007). Comparison of empirical methods for building agent-based models in land use science. Journal of Land Use Science, 2(1), 31-55. https://doi.org/10/bnvs8h.

Robinson, D.T., Di Vittorio, A., Alexander, P., Arneth, A., Barton, C.M., Brown, D.G., Kettner, A.J., Lemmen, C., O’Neill, B.C., Janssen, M., Pugh, T.A.M., Rabin, S.S., Rounsevell, M., Syvitski, J.P.M., Ullah, I., \& Verburg, P.H. (2018). Modelling feedbacks between human and natural processes in the land system. Earth System Dynamics, 9, 1-47. https://doi.org/10.5194/esd-2017-68.

Rosenberg, M., Confessore, N., and Cadwalladr, C. (2018). How Trump Consultants Exploited the Facebook Data of Millions. The New York Times, March 17, 2018, sec. Politics. https://www.nytimes.com/2018/03/17/us/politics/cambridgeanalytica-trump-campaign.html.

Rothstein, M.A. (2010). Is Deidentification Sufficient to Protect Health Privacy in Research? The American Journal of Bioethics, 10, 9, 3-11. https://doi.org/10.1080/15265161.2010.494215.

Rounsevell, M. et al. (2016) Linking Earth System Dynamics and Social System Modeling. Report of the Computational Human and Earth Systems Science (CHESS) group from the Workshop: 'Linking Earth System Dynamics and Social System Modeling', 23-25 May 2016, Boulder, Colorado, USA. Retrieved from: https://csdms.colorado.edu/wiki/CHESS on August 6th, 2018.

Sætra, H.S. (2017). Exploring the use of agent-based modelling in mixed methods research. Barataria. Revista CastellanoManchega de Ciencias Sociales, 22, 15-31. https://doi.org/10.20932/barataria.v0i22.337.

Saltelli, A., Ratto, M., Tarantola, S., \& Campolongo, F. (2006). Sensitivity analysis practices: Strategies for model-based inference. Reliability Engineering \& System Safety, 91, 10-11, 1109-1125. https://doi.org/10.1016/j.ress.2005.11.014.

Samourkasidis, A., \& Athanasiadis, I.N. (2016). A miniature data repository on a Raspberry Pi. Electronics, 6(1), 1. https://doi.org/10.3390/electronics6010001.

Sarewitz, D. (2004). How science makes environmental controversies worse. Environmental Science \& Policy, 7(5), 385-403. https://doi.org/10.1016/j.envsci.2004.06.001.

Sayama, H., Pestov, I., Schmidt, J., Bush, B.J., Wong, C., Yamanoi, J., Gross, T. (2013). Modeling complex systems with adaptive networks. Computers \& Mathematics with Applications, 65(10), 1645-1664.

Schade, S., Tsinaraki, C., \& Roglia, E. (2017). Scientific data from and for the citizen. First Monday, 22(8). https://doi.org/10.5210/fm.v22i8.7842

Scheffer, M. (2009). Critical transitions in nature and society. Princeton University Press, Princeton.

Scheffer, M., \& Carpenter, S.R. (2003). Catastrophic regime shifts in ecosystems: linking theory to observation. Trends in Ecology \& Evolution, 18:648-656. https://doi.org/10.1016/j.tree.2003.09.002.

Schimel, D., K. Hibbard, D. Costa, P. Cox, \& S. van der Leeuw (2015). Analysis, Integration and Modeling of the Earth System (AIMES): Advancing the post-disciplinary understanding of coupled human-environment dynamics in the Anthropocene. Anthropocene, 12, p 99-106.

Schmolke, A., Thorbek, P., DeAngelis, D.L., Grimm, V. (2010). Ecological modelling supporting environmental decision making: a strategy for the future. Trends in Ecology \& Evolution 25 (8), 479-486. 
Scholes, R.J., Reyers, B., Biggs, R., Spierenburg, M.J., \& Duriappah, A. (2013). Multi-scale and cross-scale assessments of social-ecological systems and their ecosystem services. Current Opinion in Environmental Sustainability, 5(1), 16-25. https://doi.org/10.1016/j.cosust.2013.01.004.

Schulze, J., Müller, B., Groeneveld, J., \& Grimm, V. (2017). Agent-based modelling of social-ecological systems: Achievements, challenges, and a way forward. Journal of Artificial Societies and Social Simulation, 20(2), 8.

Schlüter, M., Müller, B., \& Frank, K. (2019). The potential of models and modeling for social-ecological systems research: the reference frame ModSES. Ecology and Society 24(1).

Schlüter, M., Hinkel, J. Bots, P. W. G. \& Arlinghaus, R. (2014). Application of the SES framework for model-based analysis of the dynamics of social-ecological systems. Ecology and Society, 19(1), 36. https://doi.org/10.5751/ES-05782-190136.

Schlüter, M., Baeza, A., Dressler, G., Frank, K., Groeneveld, J., Jager, W., Janssen, M.A., McAllister, R.R.J., Muller, B., Orzch, K., Schwarz, N., \& Wijermans, N. (2017). A framework for mapping and comparing behavioural theories in models of social-ecological systems. Ecological Economics, 131, 21-35. https://doi.org/10.1016/j.ecolecon.2016.08.008.

Sætra, H.S., 2017. Exploring the use of agent-based modelling in mixed methods research. Barataria. Revista CastellanoManchega de Ciencias Sociales, 22, 15-31. https://doi.org/10.20932/barataria.v0i22.337.

Smajgl, A., \& Barreteau, O. (2014). Empiricism and Agent-Based Modelling. In A. Smajgl \& O. Barreteau (Eds.), Empirical Agent-Based Modelling - Challenges and Solutions (pp. 1-26). Springer New York. https://doi.org/10.1007/978-14614-6134-0_1.

Sterling, E., Zellner, M., Leong, K., Jenni, K., Gray, S., Jordan, R., Bendor, T., Jetter, A., Schmitt-Olabisi, L, Paolisso, M., Hubacek, K., Bommel, P., \& Bammer, G. (2019). Try, try again: Lessons learned from success and failure in participatory modeling. Elementa, 7.

Stern, N., (2016). Economics: Current climate models are grossly misleading. Nature, 530, 407-409. https://doi/org/10.1038/530407a.

Stodden, V., Seiler, J., \& Ma, Z. (2018). An empirical analysis of journal policy effectiveness for computational reproducibility, PNAS, 115, 2583-2589. https://doi.org/10.1073/pnas.1708290115.

Sudret, B. (2008). Global sensitivity analysis using polynomial chaos expansions. Reliability Engineering \& System Safety. 93(7), 964-979. https://doi.org/10.1016/j.ress.2007.04.002.

Taleb, N. N. (2007). The black swan: The impact of the highly improbable. Random house.

Tenkanen, H., Di Minin, E., Heikinheimo, V., Hausmann, A., Herbst, M., Kajala, L., \& Toivonen, T. (2017). Instagram, Flickr, or Twitter: Assessing the usability of social media data for visitor monitoring in protected areas. Scientific Reports, 7, 17615. https://doi.org/10.1038/s41598-017-18007-4.

Thakuriah, P., Tilahun, N., \& Zellner, M. (2016). Big Data and Urban Informatics: Innovations and Challenges to Urban Planning and Knowledge Discovery. In Seeing Cities through Big Data: Research Methods and Applications in Urban Informatics, edited by P. Thakuriah, Tilahun, N. and Zellner, M., Springer.

Tolk, A. (2015). The next generation of modeling \& simulation: integrating big data and deep learning. In Proceedings of the conference on summer computer simulation (pp. 1-8). Society for Computer Simulation International.

Tigchelaar, M., Battisti, D.S., Naylor, R.L., Ray, D.K. (2018). Future warming increases probability of globally synchronized maize production shocks. Proceedings of the National Academy of Sciences of the United States of America, 115(26), pp. 6644-6649.

Trenholm, R., Lantz, V., Martinez-Espineira, R., \& Little, S. (2013). Cost-benefit analysis of riparian protection in an eastern Canadian watershed. Journal of Environmental Management, 116(15), 81-94. https://doi.org/10.1016/j.jenvman.2012.11.039.

Trutnevyte, E., Guivarch, C., Lempert, R., \& Strachan, N. (2016). Reinvigorating the scenario technique to expand uncertainty consideration. Climatic Change, 135(3-4), 373-379. https://doi.org/10.1007/s10584-015-1585-x.

Ullah, I.I.T., Kuijt, I., \& Freeman, J. (2015). Toward a theory of punctuated subsistence change. PNAS, 112, 9579-9584. https://doi.org/10.1073/pnas.1503628112.

Ulrich, W. (2013). Critical systems thinking. Encyclopedia of Operations Research and Management Science, 314-326. https://doi.org/10.1007/978-1-4419-1153-7.

UN Global Pulse, Social Media and Forced Displacement (2017a). Big Data Analytics \& Machine-Learning, White Paper, UNHCR Innovation Service.

UN Global Pulse, Social Media and Forced Displacement (2017b). Social Media and Forced Displacement: Big Data Analytics \& Machine-Learning, White Paper, UNHCR Innovation Service.

van der Sluijs, J.P., Craye, M., Funtowicz, S., Kloprogge, P., Ravetz, J., \& Risbey, J. (2005). Combining Quantitative and Qualitative Measures of Uncertainty in Model-Based Environmental Assessment: The NUSAP System. Risk Analysis, 25(2): 481-492. https://doi.org/10.1111/j.1539-6924.2005.00604.x.

van Ittersum, M.K., Cassman, K.G., Grassini, P., Wolf, J., Tittonell, P., \& Hochman, Z. (2013). Yield gap analysis with local to global relevance-A review. Field Crops Research, 143, 4-17. https://doi.org/10.1016/j.fcr.2012.09.009.

van Nes, E.H., Arani, B.M.S., Staal, A., van der Bolt, B., Flores, B.M., Bathiany, S., \& Scheffer, M. (2016). What Do You Mean, 'Tipping Point'? Trends in Ecology \& Evolution, 31, 902-904. https://doi.org/10.1016/j.tree.2016.09.011.

van Vliet, J., Hurkens, J., White, R., van Delden, H. (2012) An activity-based cellular automaton model to simulate land-use dynamics, Environment and Planning B: Planning and Design 39(2), pp. 198-212

van Zanten, B.T., van Berkel, D.B., Meentemeyer, R.K., Smith, J.W., Tieskens, K.F., \& Verburg, P.H. (2016). Continental Scale Quantification of Landscape Values Using Social Media Data. Proceedings of the National Academy of Sciences of the United States of America. https://doi.org/10.1073/pnas.1614158113. 
Vaughan, D. (1996). The Challenger Launch Decision: Risky Technologies, Deviance, and Culture at NASA. Chicago, University of Chicago Press.

Verburg, P.H., Soepboer, W., Veldkamp, A., Limpiada, R., Espaldon, V., \& Mastura, S.S.A. (2002). Modeling the spatial dynamics of regional land use: The CLUE-S model, Environmental Management, 30(3), pp. 391-405.

Verburg, P.H., Dearing, J.A., Dyke, J.G., van der Leeuw, S., Seitzinger, S., Steffen, W., \& Syvitski, J.P.M. (2016). Methods and approaches to modelling the Anthropocene. Global Environmental Change, 39, 328-340. https://doi.org/10.1016/j.gloenvcha.2015.08.007.

Vereecken, H., R. Kasteel, J. Vanderborght, \& Harter, T. (2007). Upscaling Hydraulic Properties and Soil Water Flow Processes in Heterogeneous Soils. Vadose Zone Journal, 6:1-28. https://doi.org/10.2136/vzj2006.0055.

Vermaat, J.E., Eppink, F., van den Bergh, J.C.J.M., Barendregt, a., \& svan Belle, J. (2005). Aggregation and the matching of scales in spatial economics and landscape ecology: empirical evidence and prospects for integration. Ecological Economics, 52(2): 229-237. https://doi.org/10.1016/j.ecolecon.2004.06.027.

Villa, F., Balbi, S., Athanasiadis, I.N., \& Caracciolo, C. (2017). Semantics for interoperability of distributed data and models: Foundations for better-connected information. F1000Research, 6, 686. https://doi.org/10.12688/f1000research.11638.1.

Voinov, A., \& Bousquet, F. (2010). Modelling with stakeholders. Environmental Modelling \& Software, 25(11), 1268-1281. https://doi.org/10.1016/j.envsoft.2010.03.007.

Voinov, A., Kolagani, N., McCall, M.K., Glynn, P.D., Kragt, M.E., Ostermann, F.O., Pierce, S.A., \& Ramu, P. (2016). Modelling with stakeholders - Next generation. Environmental Modelling \& Software, 77, 196-220.

Voinov, A., Jenni, K., Gray, S., Kolagani, N., Glynn, P., Bommel, P., Prell, C., Zellner, M., Paolisso, M., Jordan, R., Sterling, E., Schmitt Olabisi, L., Giabbanelli, P., Sun, Z., Le Page, C., Elsawah, S., BenDor, T., Hubacek, K., Laursen, B., Jetter, A., Basco Carrera, L., Singer, A., Young, L., \& Brunacini, J. (2018). Tools and methods in participatory modeling: selecting the right tool for the job. Environmental Modelling \& Software, 109, 232-250.

Voinov, A., \& Shugart, H.H. (2013). 'Integronsters', integral and integrated modelling. Environmental Modelling \& Software, $39,149-158$.

Vrugt, J.A., ter Braak, C.J.F., Clark, M.P., Hyman, J.M., \& Robinson, B.A. (2008). Treatment of input uncertainty in hydrologic modeling: Doing hydrology backward with Markov chain Monte Carlo simulation, Water Resources Research, 44, W00B09. https://doi.org/10.1029/2007WR006720.

Wagener, T. \& Wheater, H.S. (2006). Parameter estimation and regionalization for continuous rainfall-runoff models including uncertainty. Journal of Hydrology, 320, 132-154.

Walker, B., Carpenter, S., Anderies, J., Abel, N., Cumming, G., Janssen, M., Lebel, L., Norberg, J., Peterson, G.D., \& Pritchard, R. (2002). Resilience Management in Social-ecological Systems: a Working Hypothesis for a Participatory Approach. Conservation Ecology, 6(1): 14. https://www.jstor.org/stable/26271859.

Walker, W.E., Harremoës, P., Rotmans, J., Van der Sluijs, J.P., Van Asselt, M.B.A., Janssen, P., \& Krayer von Krauss, M.P. (2003) Defining Uncertainty A Conceptual Basis for Uncertainty Management in Model-Based Decision Support, Integrated Assessment, 4(1), 5-17.

Walter, E., \& Pronzato, L. (1997). Identification of Parametric Models from Experimental Data. Springer Verlag, Berlin.

Wang, T. (2013). Big Data Needs Thick Data. http://ethnographymatters.net/blog/2013/05/13/big-data-needs-thick-data/.

Wang, W., Rothschild, D., Goel, S., \& Gelman, A. (2015). Forecasting Elections with Non-Representative Polls. International Journal of Forecasting, 31 (3), 980-91. https://doi.org/10.1016/j.ijforecast.2014.06.001.

Watkins, M. D., \& Bazerman, M. H. (2003). Predictable surprises: The disasters you should have seen coming. Harvard business review, 81(3), 72-85.

Weeg, C., Schwartz, H.A., Hill, S., Merchant, R.M., Arango, C., \& Ungar, L. (2015). Using Twitter to Measure Public Discussion of Diseases: A Case Study. JMIR Public Health and Surveillance, 1 (1): e6. https://doi.org/10.2196/publichealth.3953.

Wilensky, U., \& Rand W. (2007). Making Models Match: Replicating an Agent-Based Model. Journal of Artificial Societies and Social Simulation, 10(4), 2. http://jasss.soc.surrey.ac.uk/10/4/2.html.

Willcock, S., Martínez-López, J., Hooftman, D.A.P., Bagstad, K.J., Balbi, S., Marzo, A., Prato, C., Sciandrello, S., Signorello, G., Voigt, B., Villa, F., Bullock, J.M., \& Athanasiadis, I.N. (2018). Machine Learning for Ecosystem Services, Ecosystem Services, https://doi.org/10.1016/j.ecoser.2018.04.004.

Wilson, J., Low, B., Costanza, R., \& Ostrom, E. (1999). Scale misperceptions and the spatial dynamics of a social-ecological system. Ecological Economics, 31, 243-257.

Winsemius, H.C., Van Beek, L.P.H., Jongman, B., Ward, P.J., \& Bouwman, A. (2013). A framework for global river flood risk assessments, Hydrology and Earth System Sciences, 17, 1871-1892, https://doi.org/10.5194/hess-17-1871-2013.

Yang, J., Jakeman, A., Fang, G., \& Chen, X. (2018). Uncertainty analysis of a semi-distributed hydrologic model based on a Gaussian Process emulator. Environmental Modelling \& Software, 101, 289-300.

Zare, F., Elsawah, S., Iwanaga, T., Jakeman, A.J., \& Pierce, S.A. (2017) Integrated water assessment and modelling: a bibliometric analysis of trends in the water resources sector. Journal of Hydrology, 552, 765-778.

Zellner, M.L. (2008). Embracing Complexity and Uncertainty: The Potential of Agent-Based Modeling for Environmental Planning and Policy. Planning Theory \& Practice, 9 (4), 437-457. https://doi.org/10.1080/14649350802481470.

Zellner, M.L., \& Campbell, S. (2015). Planning for Deep-Rooted Problems: What Can We Learn from Aligning Complex Systems and Wicked Problems? Planning Theory and Practice, 16 (4), 457-478. https://doi.org/10.1080/14649357.2015.1084360. 
Zellner, M.L., Lyons, L., Hoch, C J., Weizeorick, J., Kunda, C., \& Milz, D. (2012). Modeling, Learning and Planning Together: An Application of Participatory Agent-Based Modeling to Environmental Planning. URISA Journal, GIS in Spatial Planning Issue, 24 (1), 77-92.

Zellner, M., Lyons, L., Milz, D., Shelley, J., Hoch, C., Massey, D., \& Radinsky, J., in press. Participatory Complex Systems Modeling for Environmental Planning: Opportunities and Barriers to Learning and Policy Innovation. In Porter, Zhao, Smitt Olabisi, and McNall (Eds.) Innovations in Collaborative Modeling, Michigan State University Press.

Zhang, X., Holt, J.B., Yun, S., Lu, H., Greenlund, K.J., \& Croft, J.B. (2015). Validation of Multilevel Regression and Post stratification Methodology for Small Area Estimation of Health Indicators From the Behavioral Risk Factor Surveillance System. American Journal of Epidemiology, 182 (2), 127-37. https://doi.org/10.1093/aje/kwv002. 